\title{
Optimizing the CSP-Calcium Looping integration for Thermochemical Energy Storage
}

\author{
A. Alovisio ${ }^{\text {a }}$, R. Chacartegui ${ }^{\text {b }}$, C. Ortiz ${ }^{\text {c, }}{ }^{*}$, J.M Valverde ${ }^{\text {c }}$, V. Verda ${ }^{\text {a }}$ \\ a Politecnico di Torino, Department of Energy Engineering, Corso Duca degli Abruzzi 24, 10129 Torino, Italy \\ b Energy Engineering Department, University of Seville, Camino de los Descubrimientos s/n, 41092 Sevilla, Spain \\ c Faculty of Physics, University of Seville, Avenida Reina Mercedes s/n, 41012 Sevilla, Spain \\ * Corresponding author. Tel.: +34 655783930 \\ E-mail address: cortiz7@us.es
}

\section{Abstract}

Thermochemical energy storage (TCES) is considered a promising technology to overcome the issues of intermittent energy generation in Concentrated Solar Power (CSP) plants and couple them with yearly electricity demand. The development of this technology could favor the commercial deployment of CSP, which is considered as a key factor for new challenges in reducing GHG emissions. Among other possibilities, using the calcium looping (CaL) process for TCES is an interesting choice mainly due to the low cost of natural $\mathrm{CaO}$ precursors such as limestone (below $\$ 10 /$ ton) and the high energy density that can be achieved (around $3.2 \mathrm{GJ} / \mathrm{m}^{3}$ ). This manuscript explores several configurations in order to maximize the performance of the CSP-CaL integration, focusing on power cycle integration in the carbonator zone. For this purpose, firstly, a discussion about the possibility of using open and closed power cycles is carried out, which leads to the conclusion that a $\mathrm{CO}_{2}$ closed cycle is more appropriate. Then, a closed regenerative $\mathrm{CO}_{2}$ Brayton cycle is analyzed in further detail and optimized by means of the pinch-analysis methodology. A main output is that high plant efficiencies (of about $45 \%$ ) can be achieved using a simple closed $\mathrm{CO}_{2}$ Brayton power cycle. The optimized integration layout shows good performances at carbonator to turbine outlet pressure ratios around 3 , thus allowing for a feasible integration of the power cycle in the CaL-TCES system.

Keywords: Calcium looping (CaL), Energy storage, Concentrated Solar Power (CSP), $\mathrm{CO}_{2}$, Thermochemical energy storage (TCES), Carbon Dioxide power cycle.

\section{Introduction}

The commercial expansion of renewable energy technologies is an urgent need to limit global warming to "well below" $2.0^{\circ} \mathrm{C}$ by 2100 and pursue $1.5^{\circ} \mathrm{C}$ above pre-industrial levels as agreed at Paris COP21 Conference [1]. Among renewable energy technologies, concentrated solar power (CSP) has a great potential for commercial expansion [2]. However, for renewable energies to achieve full autonomy from fossil fuels and to increase their feasibility a main hurdle to overcome is their inherent variability in production. Thus, efficient and low cost energy storage stands as the major technological challenge to mitigate global warming [3-5]. Moreover, large-scale energy storage is essential for a global system with high penetration of solar energy in order to increase the electric grid flexibility and avoid risks derived from transient peaks [6].

In recent years, a number of potential technologies have been proposed to store thermal energy in CSP plants. These are based upon three main concepts: sensible thermal energy storage (TES), latent heat storage and thermochemical energy storage (TCES) $[7,8]$. Sensible heat storage systems are the most mature technologies [9] and involve the use of various materials with high heat capacity such as water [7], molten salts [10-13], mineral oils [14] or ceramic materials [15]. 
A number of commercial CSP plants do already exist or are under construction [16] wherein heat is stored in molten salts and used to generate electricity overnight. Another type of storage system currently at the pilot scale level makes use of the latent heat associated with the phase change in some materials [17-20]. Phase change materials (PCM) allow attaining higher storage capacities as compared to sensible heat storage [9,21]. A third possibility consists in thermochemical energy storage (TCES), which is being increasingly investigated [22-25]. TCES basically consists of using the heat obtained from an external source such as CSP to drive an endothermic chemical reaction. When energy is needed the stored products from the reaction are brought together at the necessary conditions for the reverse exothermic reaction to occur. This releases the previously used heat for power production. The main advantages of TCES as compared to TES are a considerably higher energy density as well as the possibility of storing energy in the long term or transport it without significant losses $[22,26]$. Moreover, the sensible heat stored in the reaction products is also usable in addition to the chemically stored heat.

An appropriate reversible reaction is necessary in order to achieve an efficient and cost-effective TCES [27]. One of the most promising systems for the development of TCES at large scale is the Calcium Looping ( $\mathrm{CaL}$ ) process, which relies on the carbonation-calcination reaction of $\mathrm{CaO}$ (Eq. (1)) [28-31]. The $\mathrm{CaL}$ process begins with the decomposition of a bed of $\mathrm{CaCO}_{3}$ particulate solids in a calcination reactor (calciner) yielding $\mathrm{CaO}$ and $\mathrm{CO}_{2}$ as products. Once the sensible heat from the calciner outlet streams ( $\mathrm{CaO}$, with a similar heat capacity to molten salts, and $\mathrm{CO}_{2}$ streams) is recovered, the products are stored. Storage conditions and time are flexible and could be accommodated to the energy demand [26]. When needed, the $\mathrm{CaO}$ and $\mathrm{CO}_{2}$ products would be circulated into a carbonator reactor, where energy is obtained from the carbonation reaction:

$$
\mathrm{CaO}_{(\mathrm{s})}+\mathrm{CO}_{2(\mathrm{~g})} \rightleftarrows \mathrm{CaCO}_{3}(\mathrm{~s}) \quad \Delta \mathrm{H}_{\mathrm{r}}{ }^{0}=-178 \mathrm{~kJ} / \mathrm{mol}
$$

The CaL process has been extensively investigated as a potentially low energy penalty alternative to the use of the commercial amine based technology for $\mathrm{CO}_{2}$ capture [32-35].The main drawback is that $\mathrm{CaO}$ shows indeed a marked deactivation at the specific conditions of the $\mathrm{CaL}$ process for $\mathrm{CO}_{2}$ capture, which necessary involve regeneration of $\mathrm{CaO}$ by calcination at high temperature (around $950^{\circ} \mathrm{C}$ ) under high $\mathrm{CO}_{2}$ partial pressure and carbonation under relatively low $\mathrm{CO}_{2}$ partial pressure $[33,36,37]$. Nevertheless, thermodynamic conditions to achieve high TCES global efficiency in the CaL process are radically different than that for $\mathrm{CO}_{2}$ capture. The former involves carbonation at high $\mathrm{CO}_{2}$ partial pressure at high temperature whereas calcination can be carried out at low $\mathrm{CO}_{2}$ concentration and therefore relatively low temperatures. According to recently published thermogravimetric analysis (TGA) tests [38], the residual conversion exhibited by $\mathrm{CaO}$ derived from calcination of natural limestone can be as high as $X_{r}=0.5$ under these CSP conditions in contrast with the very small values obtained for post-combustion $\mathrm{CO}_{2}$ capture conditions $\left(X_{r}=0.08\right)$. Thus, the use of expensive Ca-based composites that might hinder the short-term commercial development of CSP would not be necessary. A main goal of the present manuscript is to analyze the CaL conditions for an optimum performance of the CSP-CaL integration.

Integration of the CaL process and CSP has been previously analyzed by other authors under considering several schemes. Tregambi et al. [39] proposed a configuration whereby $\mathrm{CaCO}_{3}$ calcination is assisted by CSP in order to lower the energy penalty associated to $\mathrm{CO}_{2}$ capture in a coal fired power plant by means of the CaL process. Zhai et al. [40] analyzed several schemes in which CSP served to recover energy in the $\mathrm{CO}_{2}$ capture system, although the contribution of CSP to the system is lower than $10 \%$. On the other hand, Edwards et al. [30] studied a CSP-CaL 
integration in which the heat produced in the carbonator reactor is used for power generation through a $\mathrm{CO}_{2} /$ air open cycle albeit with a limited efficiency critically affected by $\mathrm{CaO}$ conversion. Muñoz-Anton et al. [41] analyzed the integration of a close to critical regenerative $\mathrm{CO}_{2}$ Brayton cycle over a CSP power plant without storage, to achieve a higher cycle efficiency. A higher efficiency CSP-CaL integration was proposed by Chacartegui et al. [24] in which power generation was carried out by means of a closed $\mathrm{CO}_{2}$ power cycle.

In this work, a deep analysis of the CSP-CaL-power system integration is carried out. Departing from an open loop configuration, several layouts are explored and compared in order to improve the power system integration within the thermochemical storage system. The coupling of the $\mathrm{CaL}$ process with a closed $\mathrm{CO}_{2}$ power system is analyzed in detail to look for an optimal configuration. Full integration is investigated through application of pinch-analysis. Results demonstrate that a global efficiency above $45 \%$ may be attained at CaL conditions that favor a stable and high value of the multicycle conversion of $\mathrm{CaO}$ derived from natural limestone, which makes the proposed integration model a highly competitive option for TCES.

\section{CSP-CaL system for thermochemical energy storage}

Figure 1 shows a conceptual approach of the CSP-CaL integration for thermochemical energy storage. The cycle begins with the $\mathrm{CaCO}_{3}$ decomposition reaction (calcination), which is performed at high temperature from solar heat radiation. According to equilibrium conditions [42] and reaction kinetics, high temperatures are necessary when operating under high $\mathrm{CO}_{2}$ partial pressure (above $900^{\circ} \mathrm{C}$ ) for sufficiently fast reaction and achieve completion in short residence time [43-45]. Nevertheless, the use of superheated steam in the calciner environment allows to decrease the calcination temperature down to $700-750^{\circ} \mathrm{C}$ (as pointed out above) whereas the mixture $\mathrm{H}_{2} \mathrm{O} / \mathrm{CO}_{2}$ flowing out from the calciner reactor would be easily separable. Among the CSP power technologies, solar tower systems result the most appropriate for this purpose according to the temperature requirements. Small prototypes of solar calciner have been already developed based on fluidized beds [46,47], rotary kilns $[48,49]$ and cyclone atmospheric reactors [50].
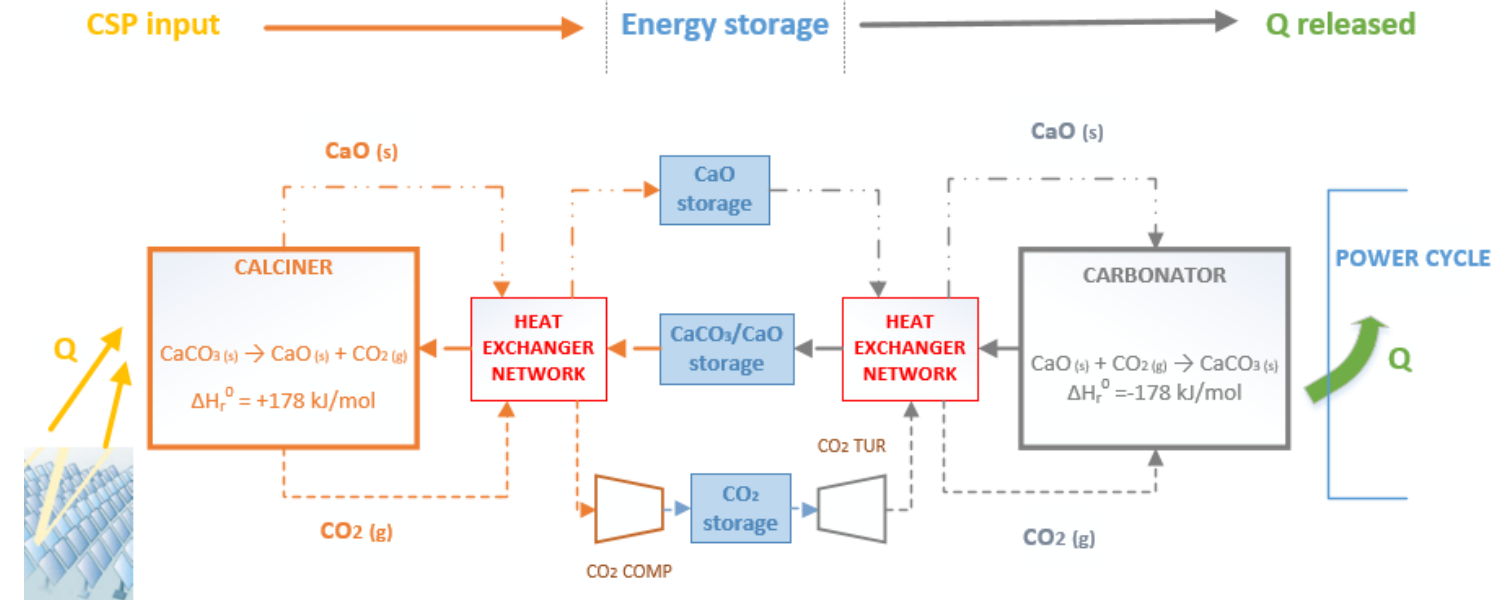

Figure 1: Conceptual CSP-CaL integration for thermochemical energy storage

As seen in Figure 1, the $\mathrm{CO}_{2}$ released after calcination is sent to a storage tank after being cooled down and compressed, whereas the $\mathrm{CaO}$ stream is circulated to a solids storage reservoir after being brought to ambient conditions. The solid stream entering the calciner, composed by $\mathrm{CaCO}_{3}$ 
and unreacted $\mathrm{CaO}$, is preheated through a heat exchanger network where the sensible heat of the hot streams leaving the calciner is used.

The energy release stage occurs in the carbonator zone, where the heat of the carbonation reaction is delivered at high temperature $\left(650-1000^{\circ} \mathrm{C}\right.$ as a function of carbonation conditions) to a power cycle by means of a stream carrier. Limestone derived $\mathrm{CaO}$ usually shows a marked deactivation at the specific conditions of the $\mathrm{CaL}$ process for post-combustion $\mathrm{CO}_{2}$ capture although, as said above, the behavior could be considerably different operating under conditions that would maximize the efficiency of the present integration [38]. Solids exiting the carbonator are passed through a heat exchanger network to preheat $\mathrm{CaO}$ and $\mathrm{CO}_{2}$ streams circulating toward the carbonator. The $\mathrm{CO}_{2}$ stream exiting the storage is expanded to a selected carbonator pressure lower than the storage pressure, which allows the use of commercial fluidized bed technology. As can be seen in iError! No se encuentra el origen de la referencia., compressionexpansion process of $\mathrm{CO}_{2}$ before and after than storage resembles a compressed air energy storage (CAES) system [8,51]. Thus, the integration incorporates energy storage not just in chemical form but also as sensible heat and mechanical energy through $\mathrm{CO}_{2}$ compression.

Regarding the integration of the power cycle in the carbonator zone, previous works have proposed the use of an air stream as heat transfer fluid in an open Brayton cycle (Figure 2) [30]. According to this scheme, the $\mathrm{CO}_{2}$ stream entering into the carbonator is assumed to react completely with the $\mathrm{CaO}$ solids to produce $\mathrm{CaCO}_{3}$. Thus, it is assumed that pure air stream exits the carbonator to enter the gas turbine for power production in an open Brayton cycle. The outflowing air from the turbine passes through a heat exchanger network, releasing sensible heat further used to preheat the solids directed into the carbonator. However, reaction equilibrium poses a fundamental limitation to this scheme since the reaction will reach equilibrium and carbonation will stop as soon as the $\mathrm{CO}_{2}$ partial pressure in the carbonator reactor is decreased to the equilibrium partial pressure as depending on the carbonator temperature. Thus, the effluent gas from the carbonator to be sent to exhaust cannot be free of $\mathrm{CO}_{2}$.

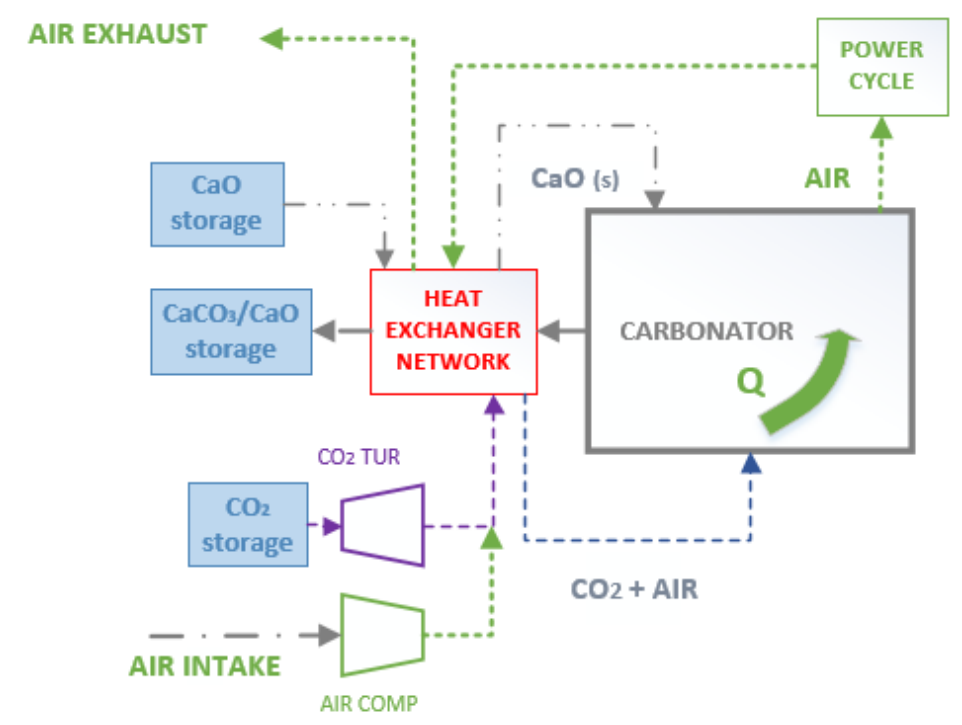

Figure 2: Air/CO2 open cycle integration in the carbonator zone. Originally proposed by Edwards et al. [30] 


$$
y_{e q}=\frac{P_{e q}}{P}=\frac{\left[4.13710^{7} \exp \left(-\frac{20474}{T+273}\right)\right]}{P}
$$

153 154 155

where $P_{e q}$ (bar) is the $\mathrm{CO}_{2}$ partial pressure at equilibrium [42] and $P($ bar), $T$ (으) are the carbonator pressure and temperature.

(a)

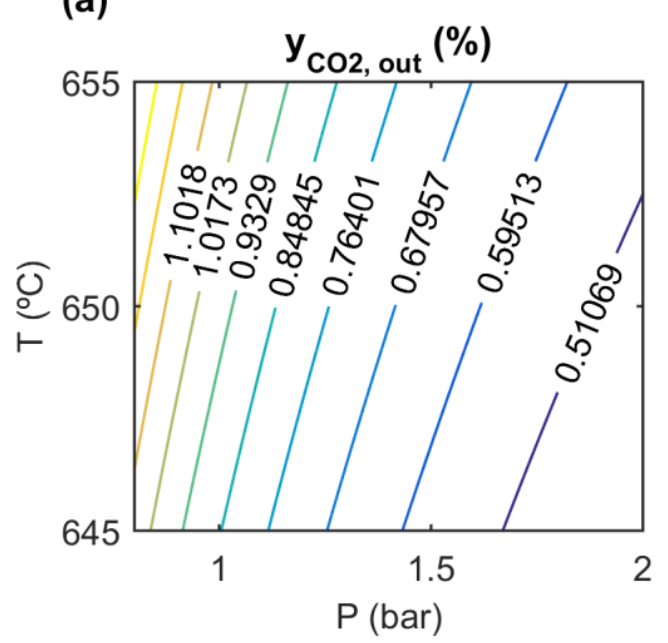

(b)

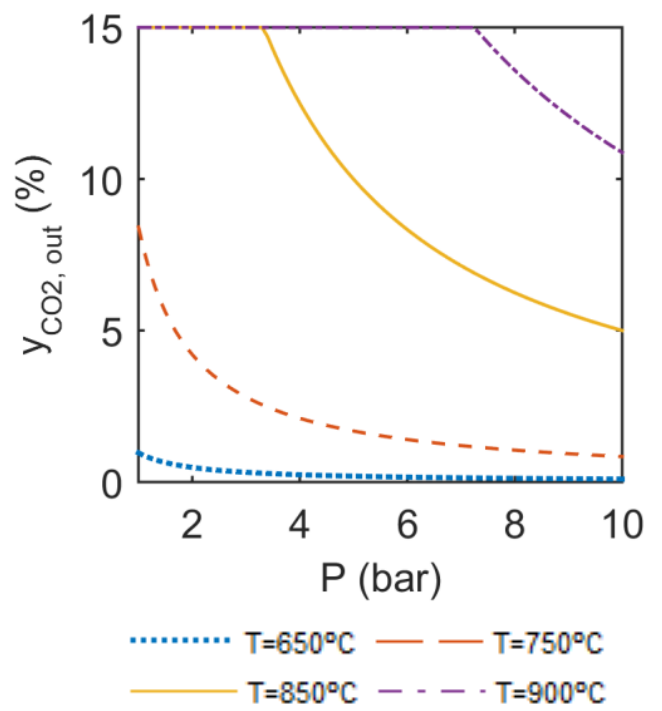

156

Thus, when a $15 \% \mathrm{v} / \mathrm{v} \mathrm{CO}_{2}$ stream is introduced into a carbonator at atmospheric pressure $(\mathrm{P}=1$ bar) and $\mathrm{T}=650^{\circ} \mathrm{C}$, the minimum $\mathrm{CO}_{2}$ concentration in the gas stream exiting the carbonator is around $1 \%$ (

Figure 3a). As can be seen in

Figure $3 \mathrm{~b}$, if the carbonator temperature is increased to $850^{\circ} \mathrm{C}$ to enhance the thermoelectric efficiency a minimum carbonator pressure higher than 4 bar is required for carbonation. This becomes even much higher ( $\mathrm{P}=50 \mathrm{bar}$ ) if the concentration of $\mathrm{CO}_{2}$ in the flue gas is reduced below $1 \%$. Moreover, the theoretical maximum of carbonation efficiency is hardly achievable in practice since it would require ideal mass and heat transfer in the gas-solid reaction. Therefore,

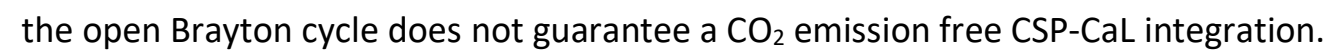

A possible solution to avoid the inconveniences of an open Brayton cycle is to use a closed $\mathrm{CO}_{2}$ Brayton cycle [24]. In this configuration, solids in the carbonator ( $\mathrm{CaO}$ ) are fluidized by a pure $\mathrm{CO}_{2}$ gas flow with a molar rate well above the stoichiometric value. The $\mathrm{CO}_{2}$ fraction not participating in the reaction is employed to remove heat from the carbonation and is delivered to a gas turbine for the power cycle. In the next section an energy optimized process leading to a global CSP-CaL integration efficiency above $43 \%$ with high feasibility index is described in detail. 


\section{CSP-CaL integration model}

179 This section shows the global integration model and the process design to transform an air-open 180 power cycle (Figure 2) to a closed- $\mathrm{CO}_{2}$ power cycle as a first step for optimizing the CSP-CaL integration. Optimal CSP-CaL integration in our work starts from the heat exchanger network proposed in [30] with the necessary adaptations derived from the use of a $\mathrm{CO}_{2}$ closed Brayton cycle in the carbonator side. Figure 4 shows a first possible approach for the proposed integration in which the new equipment needed for the closed cycle is marked by the shaded area. As can be seen, solids entering into the calciner are preheated using the sensible heat released by the hot streams leaving this reactor in a gas-solid heat exchanger (HXB in Figure 4) and in a solid-solid heat exchanger ( $\mathrm{HXA})$. The $\mathrm{CO}_{2}$ power cycle is a closed and regenerative cycle in which the heat removed by the reactants in the carbonator is recovered in a solid-gas heat exchanger (HXF). On the other hand, the residual heat from the solids at the carbonator output is extracted to pre-heat the $\mathrm{CO}_{2}$ stream entering the carbonator by means of another gas-solid heat exchanger (HXE). Solids can be conveyed by means of the mature pneumatic technology, which energy consumption is about 3-5 MJ ton-1/100 $\mathrm{m}$ [52].

193 As detailed in Figure 4, part of the power needed in the compression stage of the Brayton cycle is provided by the expansion of the pressurized $\mathrm{CO} 2$ coming from the storage vessel. The expansion of $\mathrm{CO} 2$ yields useful work while, at the same time, releases very low temperature heat (up to $-30^{\circ} \mathrm{C}$ to be spent for $\mathrm{CO}_{2}$ intercooling compression of the stream coming from carbonator). 


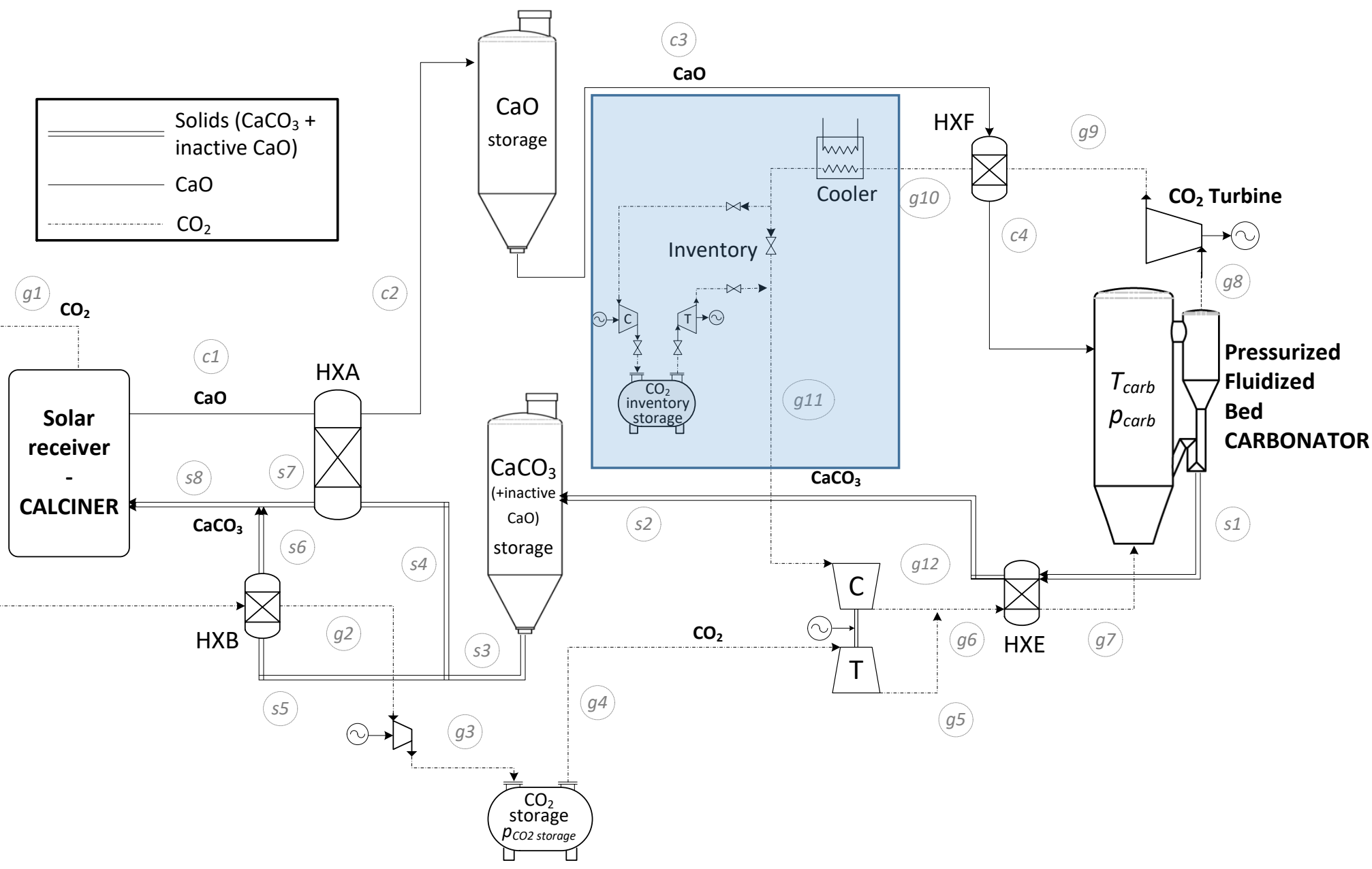


201

In this section the main aspects of the CSP-CaL integration model are described, concerning mass and energy balances in the heat exchangers, reservoirs and reactors. iError! No se encuentra el origen de la referencia. shows the mass flow scheme in the $\mathrm{CaL}$ process. The solids stream $\left(\mathrm{CaO} / \mathrm{CaCO}_{3}\right.$ mixture) entering into the carbonator (flow rate $F_{R, c l c}$ ) reacts with the $\mathrm{CO}_{2}$ stream coming from calciner side. Due to the possible loss of $\mathrm{CaO}$ reactivity with the number of cycles and depending on residence times and mass/heat transfer conditions, only a part of the solids is assumed to react $\left(F_{C a O, c r b}\right)$ to produce $\mathrm{CaCO}_{3}$. Thus, the solids at the carbonator outlet $\left(F_{R, c r b}\right)$ consist of the $\mathrm{CaCO}_{3}$ produced by carbonation $\left(F_{\mathrm{CaCO}}\right)$ and the unreacted $\mathrm{CaO}\left(F_{\mathrm{CaO}, \mathrm{nr}, \mathrm{crb}}\right)$. The stream $F_{\text {heat }}$ is the $\mathrm{CO}_{2}$ molar flow used to remove the heat of reaction from the carbonation environment and to perform the power cycle for generation of electricity, which is in this proposed cycle a $100 \% \mathrm{CO}_{2}$ stream. The carbonated particles are assumed to attain complete decomposition in the calciner. Thus, each mole of $\mathrm{CaCO}_{3}$ gives rise to a mole of $\mathrm{CO}_{2}$ and a mole of regenerated $\mathrm{CaO}\left(F_{\mathrm{CaO}, \mathrm{clc}}\right)$. The calciner solids output will therefore consist of $\mathrm{CaO}$ (partially regenerated $\mathrm{CaO}$ and partially unreacted $\mathrm{CaO}$ ) at a flow rate $F_{R, c l c}$.

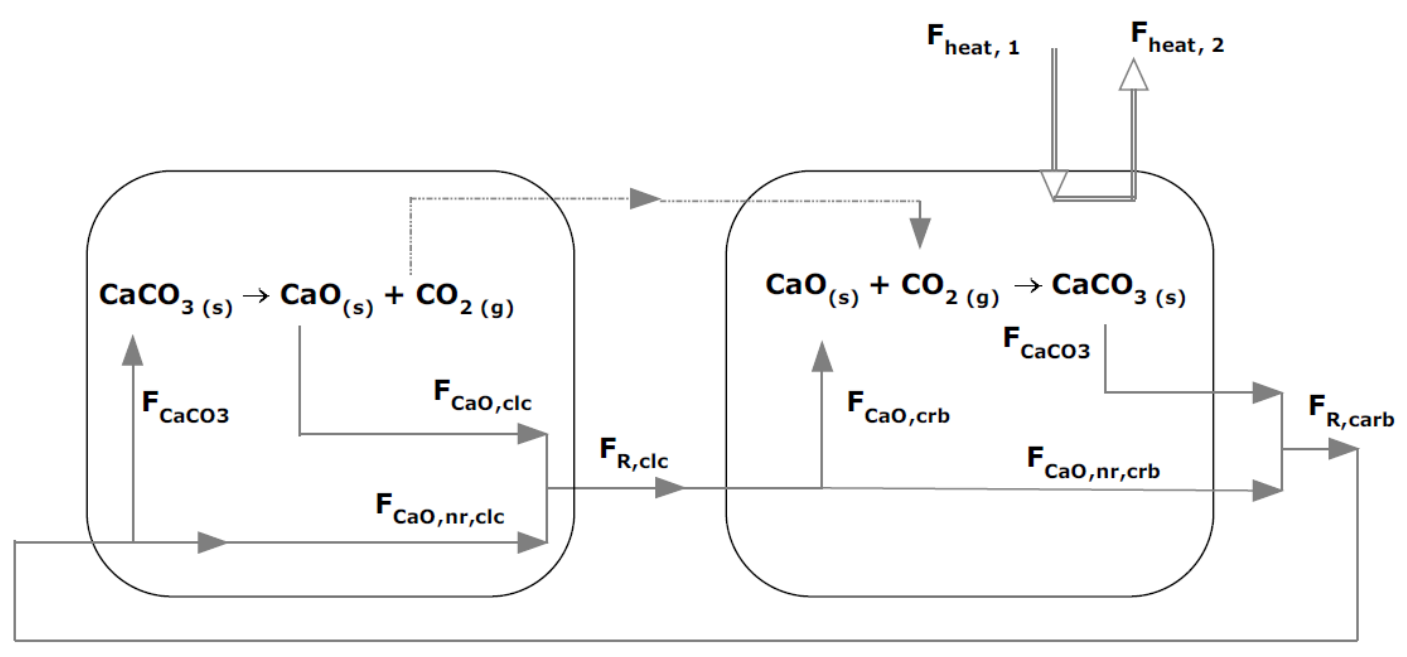

Figure 5: Mass-balance schematics of the plant.

The storage vessels must be sized to allow for a buffer storage that enables the carbonator/turbine group running over $24 \mathrm{~h}$ by an adequate load adjustment. In order to guarantee $24 \mathrm{~h}$ steady-state operation, the mass-balance equation that must be satisfied is:

$$
\int_{24 h} F_{C a C O 3, c l c}(t) d t=\int_{24 h} F_{C a C O 3, c r b}(t) d t
$$

Plant performance is determined as an average over the 24 hours period and the molar flow rates are assumed constant and equal to the integral average value over the daytime curve. Accordingly, an average daytime period $\Delta t_{\text {sun }}$ is considered during which the sun-solar concentrators system is able to provide sufficient energy for the decomposition reaction to be fully achieved in the calciner.. In this way, it is possible to derive an averaged ratio between the circulating flow rates in the calciner and carbonator side of the plant. For a daytime of $8 \mathrm{~h}$ (assuming clear skies), the average ratio over the 24 hours between the circulating flow rates of 
the streams in the calciner and in the carbonator over the 24 hours will be equal 3 , while in case the daytime is $12 \mathrm{~h}$, the flow rates through the calciner will be twice that through the carbonator. More sophisticated control strategies should be actuated within a framework of long-period control to ensure steady operation over periods larger than $24 \mathrm{~h}$. This control should be based on the meteorological forecasts and according to the power load curve.

234 On the other hand, energy balances of the calciner and carbonator are shown in Figure 6 . The energy and mass balances in the carbonator and calciner reactors can be expressed as:

$$
\begin{gathered}
\sum_{i} F_{i, \text { out }} h_{i, \text { out }}-\sum_{i} F_{i, \text { in }} h_{i, \text { in }}=\Phi-\dot{W} \\
F_{i, \text { out }}-F_{i, \text { in }}=\xi v_{i}
\end{gathered}
$$

237 where $F_{i}$ is the molar flow and $h_{i}$ is the molar enthalpy of component $i . \Phi$ and $\dot{W}$ represent 238 respectively the thermal and mechanical power interchange between the system and its surroundings. $\xi$ is the reaction rate of the considered equilibrium reaction and $v_{i}$ is the stoichiometric coefficient of compound $i$.

241 Considering the outlet flows in the same conditions of the reactor, eqs. (4) and (5) can be rearranged as:

$$
\xi \Delta H_{R}\left(T_{\text {react }}\right)+\sum_{i} F_{i, \text { in }}\left(h_{i, \text { react }}-h_{i, \text { in }}\right)=\Phi-\dot{W}
$$

where $\Delta H_{R}\left(T_{\text {react }}\right)$ is the reaction enthalpy change at the reaction temperature.

$$
\Delta H_{R}\left(T_{\text {react }}\right)=\sum_{i} v_{i} h_{i, T}=\Delta H_{R}^{0}+\sum_{i} v_{i} \int_{\text {ref }}^{T} c_{p, i} d T
$$

Energy change in the control volume consists therefore of the part associated to the heat of reaction at reactor temperature $\left(\xi \Delta H_{R}\left(T_{\text {react }}\right)\right)$ and the heat required to bring reactants from inlet to reactor condition $\left(\sum_{i} F_{i, \text { in }}\left(h_{i, \text { react }}-h_{i, \text { in }}\right)\right)$. 


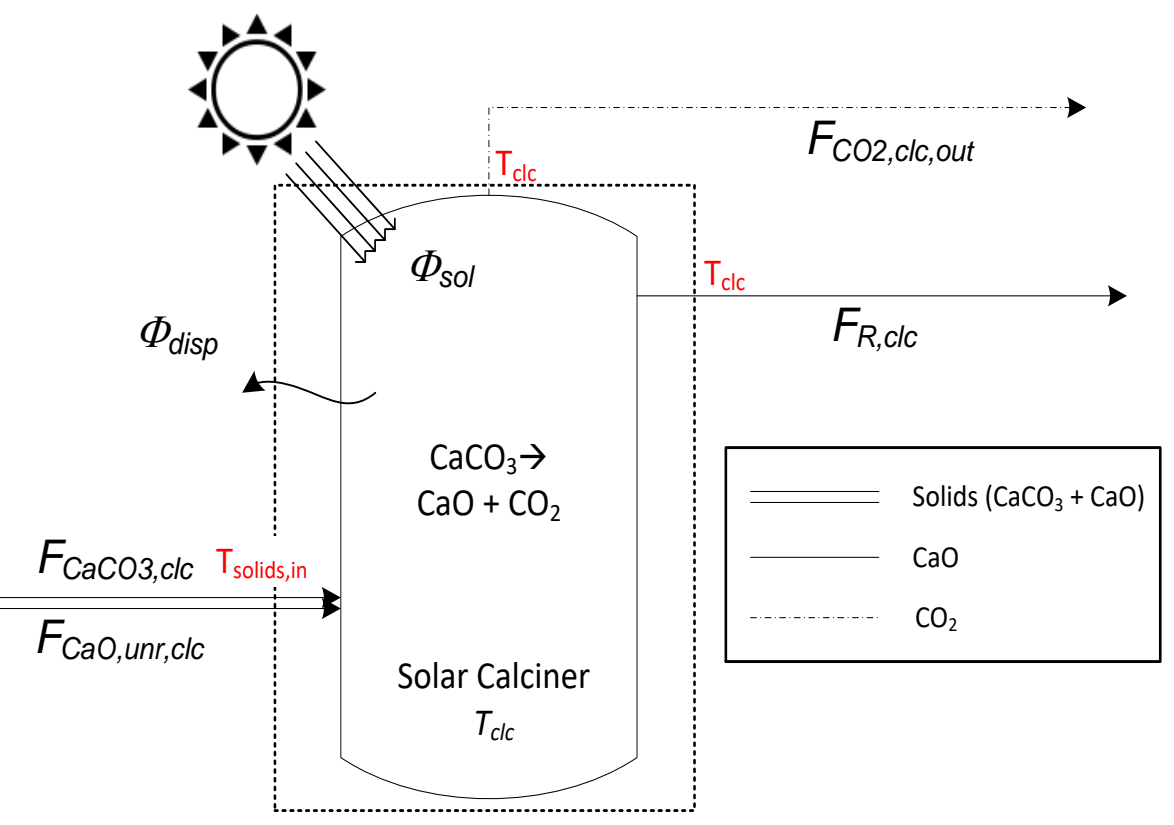

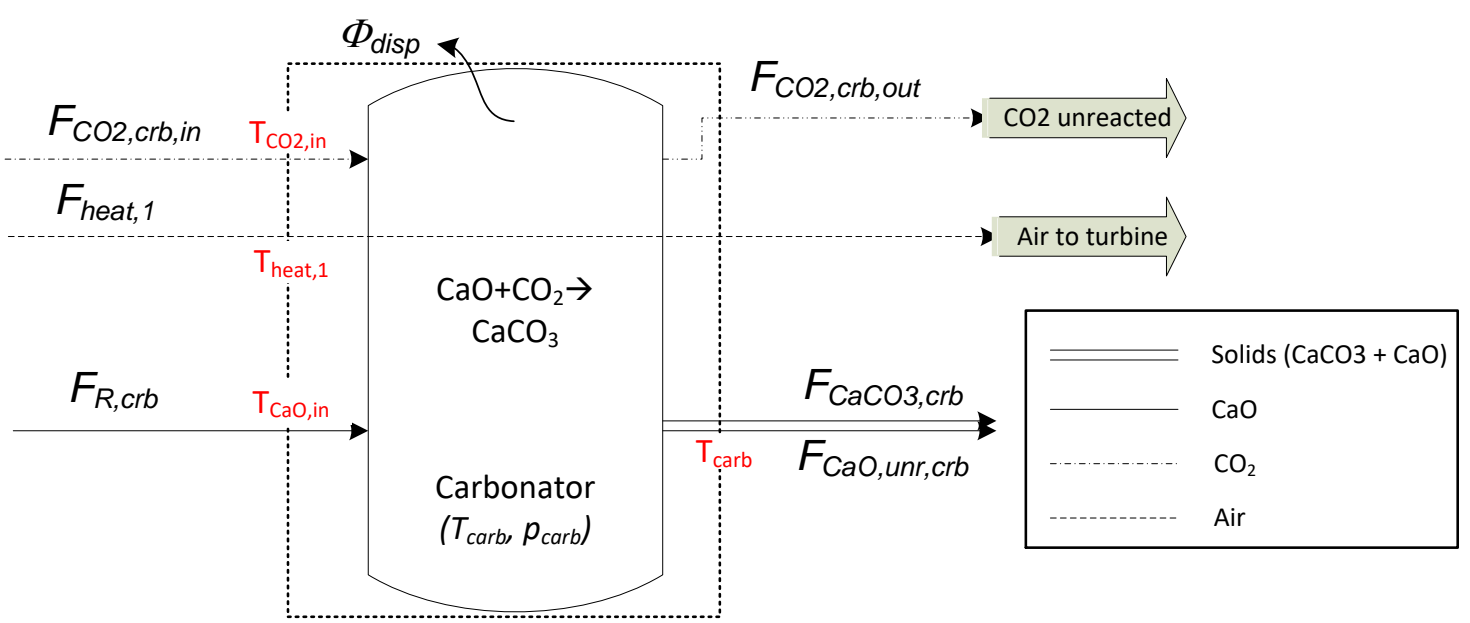

Figure 6: Energy balance in the calciner (top) and carbonator (bottom) reactors.

Assuming reactor isothermal conditions, Eq. (6) applied to the carbonator serves to balance out the amount of $\mathrm{CO}_{2}$ needed to remove the heat which is not absorbed by reactants or dispersed through the walls. On the other hand, Eq. (6) applied to the calciner yields the $\mathrm{CaCO}_{3}$ decomposition in accordance to the net energy input into the system given by the balance of solar heat supply and energy loss occurring between the sun and the reactor (due to undesirable heat transfer, radiation, absorption losses or reflection effects).

The carbonator, which is a pressurized fluidized bed wherein the carbonation reaction takes place at high temperature. Pressurized carbonation is desirable for the power-cycle direct integration and allows carbonation at high temperatures and at a fast rate [53]. The solids in the carbonator $(\mathrm{CaO})$ are fluidized by a pure $\mathrm{CO}_{2}$ gas flow. Thus, the molar flow rate of $\mathrm{CO}_{2}$ flowing into the carbonator is well above the stoichiometric need. The $\mathrm{CO}_{2}$ fraction which does not intervene in the reaction is used to remove heat from carbonation and deliver it to the gas 
turbine. Let us define a parameter $E$ to quantify the fraction of $\mathrm{CO}_{2}$ spent in the reaction (Eq. (8)), so that the non-reacting fraction of $\mathrm{CO}_{2}$ is just re-circulating in the loop:

269

270

271

272

273

274

275

276

277

278

279

280

281

282

283

284

285

286

287

288

289

$$
E=\frac{\text { mol } \mathrm{CO}_{2} \text { reacted }}{\mathrm{mol} \mathrm{CO}_{2} \text { in }}=1-\frac{F_{\mathrm{CO}_{2}, \text { out }}}{F_{\mathrm{CO}_{2}, \text { in }}}=1-\frac{F_{\mathrm{CO}_{2}, \text { power cycle }}+F_{\mathrm{CO}_{2}, \text { nr }}}{F_{\mathrm{CO}_{2}, \text { power cycle }}+F_{\mathrm{CO}_{2}, \text { stoich }}}
$$

Here $\mathrm{F}_{\mathrm{CO}_{2}, n r}$ is the non-reacting portion of the $\mathrm{F}_{\mathrm{CO}_{2} \text {, stoich }}$ stoichiometric moles of $\mathrm{CO}_{2}$ needed for the reaction. The $\mathrm{CO}_{2}$ cycle is a closed and regenerative cycle, where the heat removed by reactants in the carbonator is recovered in an indirect gas-solid heat exchanger, HXF (see Figure 4). This avoids the direct contact between $\mathrm{CO}_{2}$ and $\mathrm{CaO}$ streams, which could lead to a partial carbonation reaction with a possible poor utilization of the reaction heat. In the heat exchanger $\mathrm{HXF}$, heat from the exhaust $\mathrm{CO}_{2}$ stream is used to heat up the solids before entering the carbonator, while in the heat exchanger HXE (see Figure 4) the residual heat from the solids leaving the carbonator is used to pre-heat the $\mathrm{CO}_{2}$ at the carbonator inlet. Part of the power needed in the compression stage of the $\mathrm{CO}_{2}$ Joule-Brayton cycle is provided from the expansion of the pressurized $\mathrm{CO}_{2}$ needed to run the reaction in the carbonator. Expansion in the gas turbine finally supplies the useful power of the cycle. $\mathrm{CO}_{2}$ expansion from storage also provides some usable work, and at the same time releases useful energy at very low temperature (up to $-30^{\circ} \mathrm{C}$ ), which can be employed for the $\mathrm{CO}_{2}$ intercooling compression of the stream coming from carbonator. For this reason, $\mathrm{C}$ and $\mathrm{T}$ (see Figure 4) are thermally coupled to avoid the use of massive air cooling devices (and to further reduce costs).

\subsection{Layout 1 simulation}

The schematic proposed in Figure 4 was simulated in order to calculate the cycle efficiency with energy storage, which is defined by the following expression:

$$
\eta=\frac{\int_{24 h} \dot{W}_{\text {net }}}{\int_{24 h} \dot{Q}_{\text {input }}}
$$

where $\dot{W}_{\text {net }}$ is the net power produced in the global cycle and $\dot{Q}_{\text {input }}$ is the CSP input in the calciner.

The values of the operation parameters used for this purpose are summarized in

Table 1. The cycle performance is analyzed as a function of four key parameters for cycle efficiency, namely $\mathrm{CaO}$ conversion $X$ (defined as the ratio of $\mathrm{CaO}$ mass converted to $\mathrm{CaCO}_{3}$ to the $\mathrm{CaO}$ mass entering the carbonator), the carbonator temperature $T_{c a r b}$, the carbonator pressure $p_{\text {carb }}$ and the $\mathrm{CO}_{2}$ main turbine outlet pressure $p_{\text {out,turbine }}$. 
Table 1: Fixed model conditions in $\mathrm{CO}_{2}$ closed power cycle configuration

\begin{tabular}{lrll}
\hline Net absorbed solar flux in calciner & 100 & $\mathrm{MW}$ \\
\hline Thermal dispersions in carbonator & 10 & $\%$ \\
\hline Calciner temperature & 900 & ${ }^{\circ} \mathrm{C}$ \\
\hline Ambient temperature & 20 & ${ }^{\circ} \mathrm{C}$ \\
\hline CaO conversion $(\mathrm{X})$ & 0.20 & \\
\hline Carbonator temperature $\left(T_{\text {carb }}\right)$ & 875 & ${ }^{\circ} \mathrm{C}$ \\
\hline Carbonator pressure $\left(p_{\text {carb }}\right)$ & 6 & $\mathrm{bar}$ \\
\hline Turbine outlet pressure $\left(p_{\text {out }}\right.$ turbine & 0.2 & $\mathrm{bar}$ \\
\hline Approach temperature solid-solid $\mathrm{HX}$ & 20 & ${ }^{\circ} \mathrm{C}$ \\
\hline Approach temperature solid-gas $\mathrm{HX}$ & 15 & ${ }^{\circ} \mathrm{C}$ \\
\hline Approach temperature $\mathrm{CO}_{2}$ cooler & 10 & ${ }^{\circ} \mathrm{C}$ \\
\hline Intercoolings in CO & storage compression & 5 & \\
\hline Intercoolings in CO & cycle compression & 4 & \\
\hline CO ${ }_{2}$ storage conditions & $75 \mathrm{bar}, \mathrm{T}$ ambient \\
\hline Solid phase conveying energy consumption & 10 & $\mathrm{MJ} /$ ton $/ 100 \mathrm{~m}$ \\
\hline Equivalent length for solids conveying (carbonator & 100 & $\mathrm{~m}$ \\
side) & & \\
\hline Equivalent length for solids conveying (calciner side) & 100 & $\mathrm{~m}$ \\
\hline Daylight hours (constant solar flux) & $12 \mathrm{~h}$ & \\
\hline Isentropic efficiencies (compression/expansion) & 0.89 & \\
\hline
\end{tabular}

311 A key parameter for the cycle performance is the carbonator temperature $T_{\text {carb }}$. The 312 temperature at which carbonation is carried out is the heat-release temperature of the storage system to the power cycle. When the combination of temperature and $\mathrm{CO}_{2}$ partial pressure yields an equilibrium molar fraction of $\mathrm{CO}_{2}$ equal to the inlet molar fraction, carbonation is not possible anymore $\left(\mathrm{F}_{\mathrm{CO}_{2}, n r}=F_{\mathrm{CO}_{2} \text {, stoich }}\right)$. Thus, increasing the carbonator pressure allows shifting the carbonation temperature to higher values (see Eq. 2). For example, carbonator temperatures of $950-975^{\circ} \mathrm{C}$ are potentially achievable in the case of carbonation under pure $\mathrm{CO}_{2}$ at a pressure of 7 bar and $1025-1050^{\circ} \mathrm{C}$ would be achievable in case of 15 bar.

The results obtained for the global plant efficiency are plotted in Figure 7 as a function of the carbonator temperature and for two fixed values of $\mathrm{CaO}$ conversion $(X=0.2$ and 0.5$)$. As can be seen, the plant efficiency would be hampered by a $\mathrm{CaO}$ conversion higher than 0.2 . However, a high $\mathrm{CaO}$ conversion should help one increasing the cycle performance since a minor fraction of unreacted $\mathrm{CaO}$ would be present in the circulating stream of solids, therefore allowing for a reduction of the energy penalty. This suggests that the performance of the CSP-CaL integration could be improved by optimizing the heat recovery exchanger network as will be discussed in the next sections. 


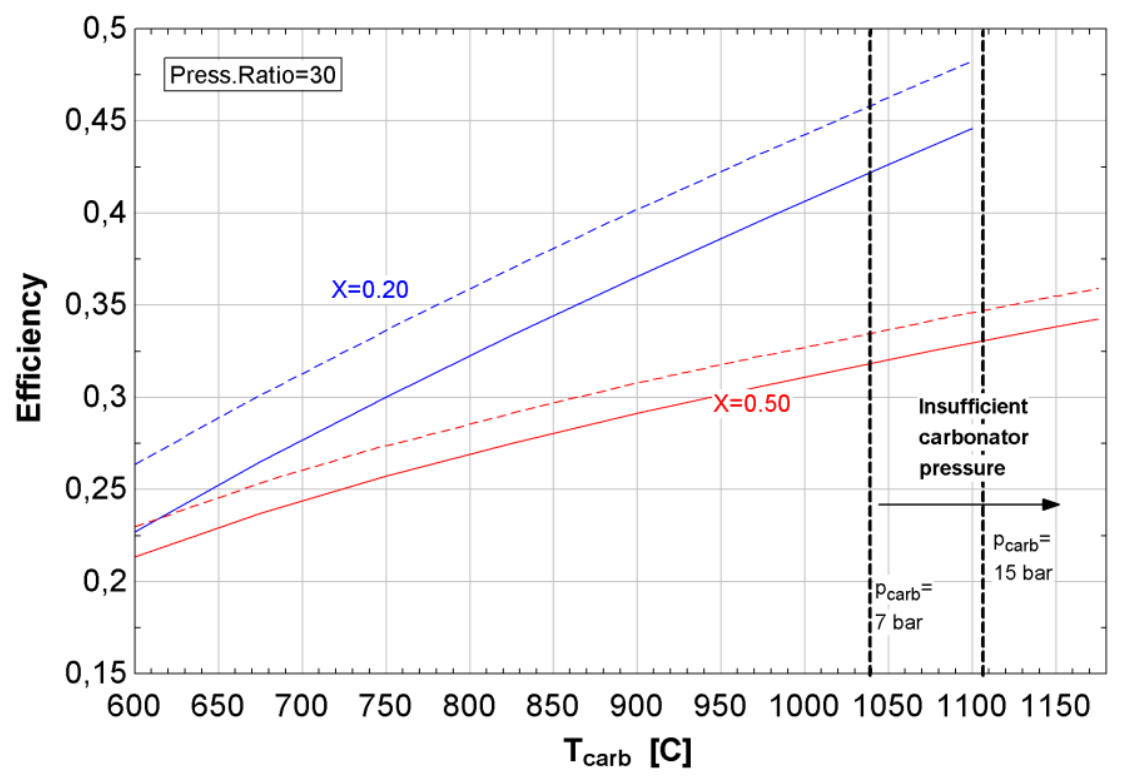

Figure 7: Efficiency vs carbonator temperature $(P R=30)$ calculated for fixed values of $\mathrm{CaO}$ conversion $\mathrm{X}=0.20$ and $X=0.50$ (solid lines). Dashed lines show efficiency calculated without including energy consumption for solid conveying. Temperature limits due to equilibrium constrains are marked for carbonator pressures of 7 bar and 15 bar.

Another critical parameter for the system performance is the pressure ratio in the main turbine, defined as $P R=p_{\text {carb }} / p_{\text {out,turbine. }}$. On the other hand, the global cycle efficiency has a dependence also on the absolute carbonator and turbine outlet pressures. Figure 8 shows a contour plot of the system efficiency as a function of both carbonator pressure and turbine outlet pressure, which serves to infer the optimum pressure choice. In layout $1, \mathrm{CaO}$ conversion $(X)$ has been fixed to 0.2 which gives a close to maximum cycle efficiency.

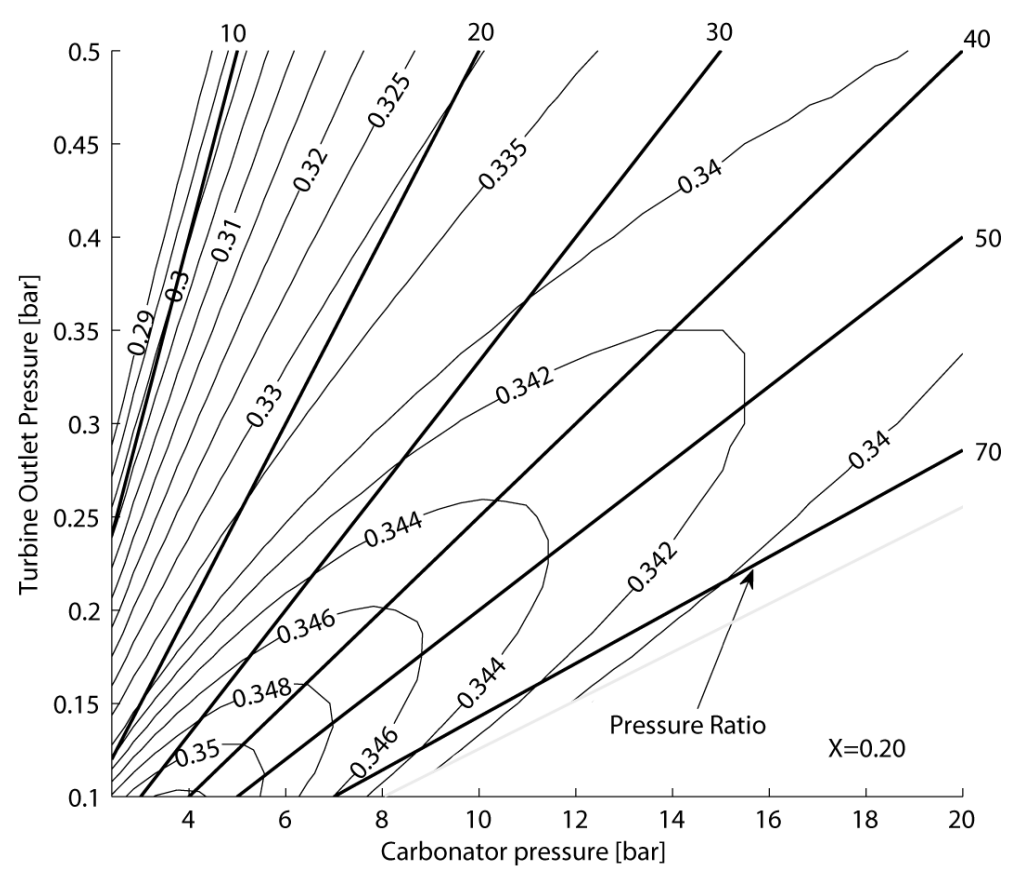

Figure 8: Efficiency as a function of carbonator and turbine outlet pressure calculated for a fixed value of $\mathrm{CaO}$ conversion $\mathrm{X}=0.20$. Dashed white lines indicate iso-efficiency cycle values. 
As shown in Figure 8, the maximum efficiency occurs at pressure ratios around 40-50. However, it is important to note that for pressure ratios over 30 the efficiency does not change considerably. From pressure ratios of 30 up to 70 , efficiency increases less than $0.5 \%$. Since such high values of pressure ratios are difficult to achieve in practice, a pressure ratio of 30 represents a good trade-off.

Figure 8 shows that higher efficiency can be achieved by decreasing the turbine outlet pressure. There are at least two reasons for which expansion to under-atmospheric pressures should be taken into consideration: i) If the turbine outlet pressure is atmospheric, the optimum pressure occurs at too high values (around 30 bar) currently unpractical from the pressurized carbonator technology; ii) Efficiency increases markedly with decreasing the turbine outlet pressure, mainly thanks to the higher power generated by decompressing the stored $\mathrm{CO}_{2}$. When the turbine outlet pressure is around 0.1 bar, for instance, efficiency is almost $1 \%$ higher than when outlet pressure is 0.3 bar. Over-expanding up to under-atmospheric pressures is not a problem in itself although it must be taken into account that too strong vacuums are difficult to manage from the practical point of view and may lead to increased pipelines volume.

As a summary, the analysis of layout 1 shows that:

- The best performances are achieved for pressure ratios in the range 40-50 (if intercooling is performed during compression of the power fluid). Nevertheless, pressure ratios over 30 do not enhance efficiency beyond $0.1-0.2 \%$, thus a good tradeoff is to keep the pressure ratio around 30.

- Such high optimum values of the pressure ratio suggest the necessity of over-expanding up to a pressure below atmospheric. Over-expansion also results in better performances (higher efficiency).

- On the other side, the higher the carbonator pressure the higher carbonator temperatures may be, which yields a higher efficiency.

- In this configuration (layout 1 ), global efficiency is hampered by an increase of $\mathrm{CaO}$ conversion due to a non-optimized heat integration as shown in next sections.

\section{Improving the heat exchange recovery in the power production stage to optimize the CSP-CaL-power cycle integration performance.}

Figure 9 shows a first modification of layout 1 (Figure 4) oriented towards improving the heat exchange recovery in order to enhance the system performance through increase of $\mathrm{CaO}$ conversion. With respect to the preliminary configuration, a $\mathrm{CO}_{2}$ regenerator $(\mathrm{HXG})$ is incorporated in the heat exchanger train in order to heat up a fraction of the gas stream entering the HXE exchanger (and then in the carbonator) using the sensible heat of a portion of the $\mathrm{CO}_{2}$ turbine output flow. The two $\mathrm{CO}_{2}$ streams, which are separately conditioned through heat exchangers HXF and HXG, are rejoined to evolve in the closed loop power-cycle. By regulating the $\mathrm{CO}_{2}$ split ratios (i.e. the fractions of the $\mathrm{CO}_{2}$ stream respectively sent to $\mathrm{HXG}$ and HXF), the internal overall heat exchange can be optimized. Thus, layout 2 offers a wider range of regulating possibilities for efficiency rise. As shown in Figure 10, Layout 2 shows higher performances as $\mathrm{CaO}$ conversion is increased. The additional $\mathrm{CO}_{2}$ storage vessel ( $\mathrm{CO} 2$ inventory storage) is included in the scheme as an inventory control strategy for the gas turbine. Since mass flow rate is one of the parameters that determines the power output of the $\mathrm{CO} 2$ closed-cycle (along with the compressor inlet temperature, turbomachinery efficiencies and the pressure ratio) [54], power generation can be controlled in the CSP-CaL scheme by modifying the circulating mass flow in the cycle (by injecting or removing $\mathrm{CO}_{2}$ using the $\mathrm{CO}_{2}$ inventory storage) to respond to a load change $[55,56]$. 


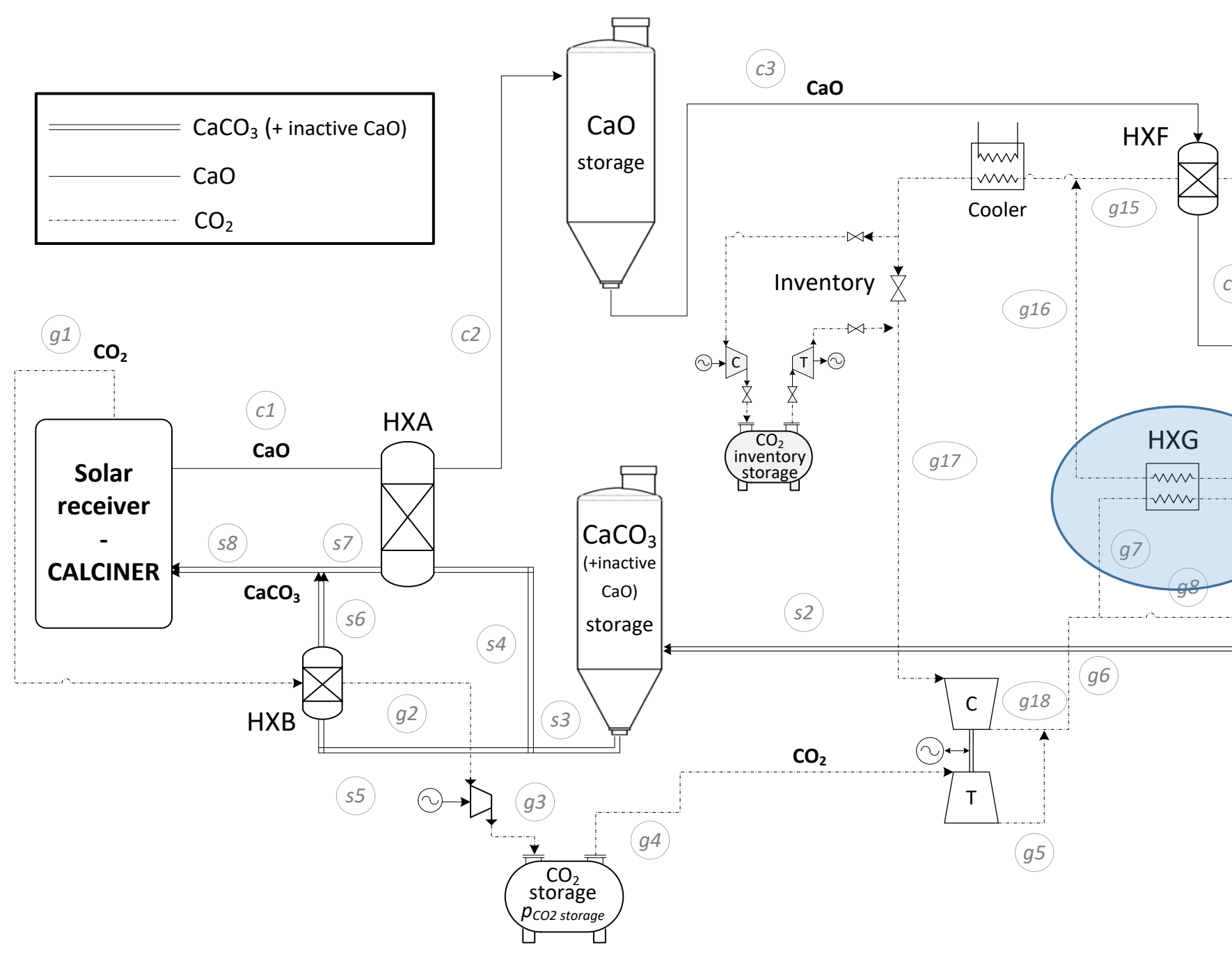




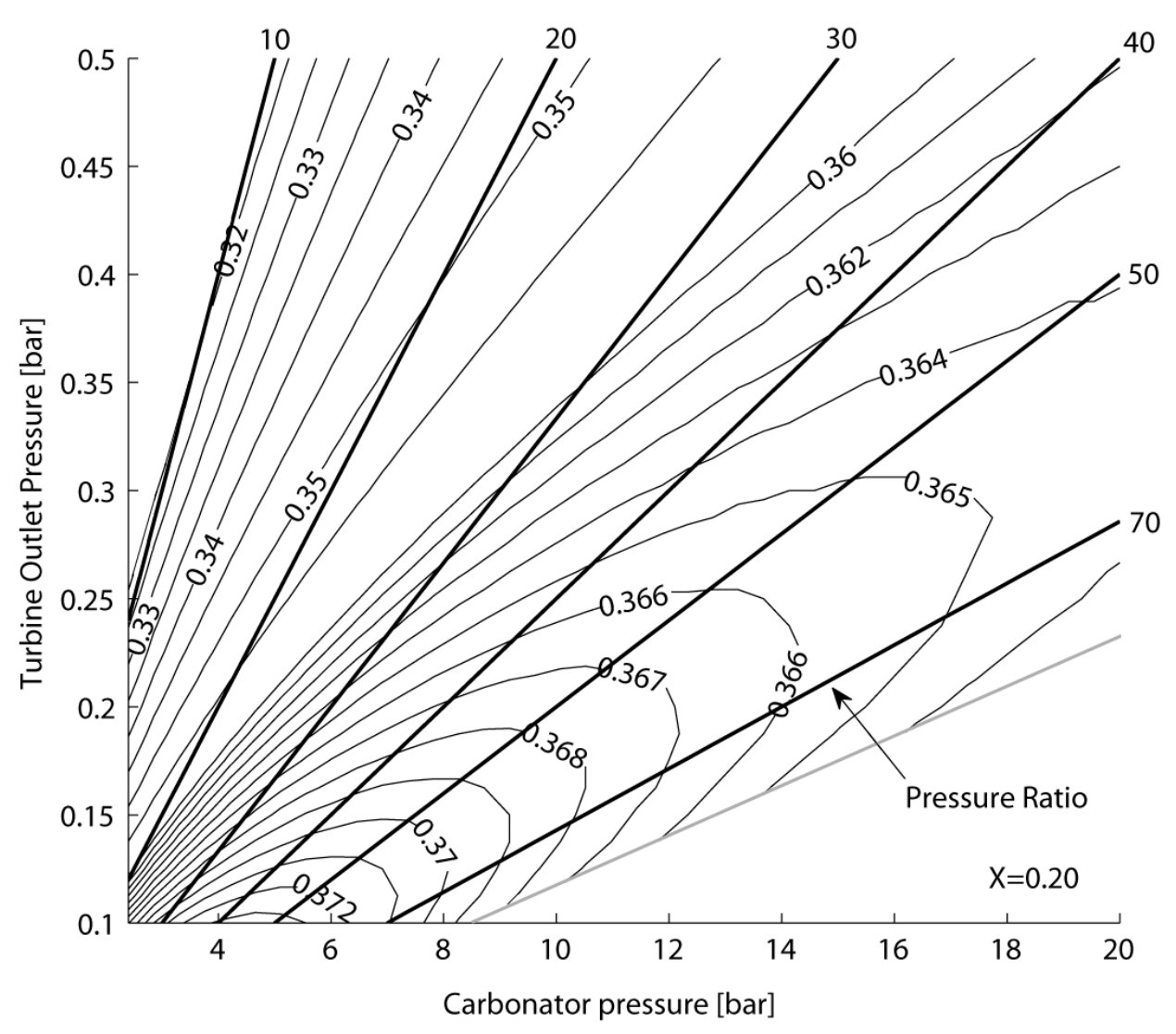

Figure 10: Efficiency as a function of carbonator and turbine outlet pressure calculated using layout 2 configuration (Figure 9) and for a fixed value of $\mathrm{CaO}$ conversion $\mathrm{X}=0.20$. Dashed white lines show iso-efficiency curves.

Figure 10 shows the new cycle (layout 2) efficiency with respect to pressure inferred from the simulations using the same inlet parameters as for layout 1 . Higher efficiency values are achieved for layout 2 as a result of an enhanced heat recovery at the carbonator outlet. As for layout 1 , a fixed value of $\mathrm{CaO}$ conversion is set to $X=0.2$. Further improvement can be achieved by a deeper thermal optimization of the system as discussed below.

\subsection{Pinch-analysis}

This section presents a pinch-analysis [57] of the carbonator side with the goal of achieving a plant configuration showing minimum energy consumption in a wide range of operational conditions.

\subsubsection{Streams identification}

Four streams can be identified in the carbonator side as detailed in Table 2 and Figure 11. Heat transfer will be characterized by the minimum temperature approach $\left(\Delta T_{\min }\right)$, which is set in a first approximation to $10^{\circ} \mathrm{C}$. The hot $\mathrm{CO}_{2}$ stream flowing out from the turbine (which needs to be cooled) and the cold $\mathrm{CO}_{2}$ stream in the pre-heating stage are indicated as $\mathrm{CO}_{2, c}$ and $414 \mathrm{CO}_{2, p}$ respectively. 
Table 2: Streams identification in the carbonator side

\begin{tabular}{ccccc}
\hline Stream & Description & Type & $\boldsymbol{T}_{\text {in }}$ & $\boldsymbol{T}_{\text {out }}$ \\
\hline 1 & $\mathrm{CO}_{2}$ at turbine output $\left(\mathrm{CO}_{2, c}\right)$ & Hot & $T_{\text {out }, \text { turbine }}$ & $T_{\text {amb }}$ \\
\hline 2 & $\mathrm{CO}_{2}$ at compressor output $\left(\mathrm{CO}_{2, p}\right)$ & Cold & $T_{\text {out }, \text { compressor }}$ & $T_{\text {carb }}$ \\
\hline 3 & $\mathrm{CaO}$ & Cold & $T_{\text {amb }}$ & $T_{\text {carb }}$ \\
\hline 4 & Solids $\left(\mathrm{CaCO}_{3}+\mathrm{CaO}\right)$ & Hot & $T_{\text {carb }}$ & $T_{\text {amb }}$ \\
\hline
\end{tabular}

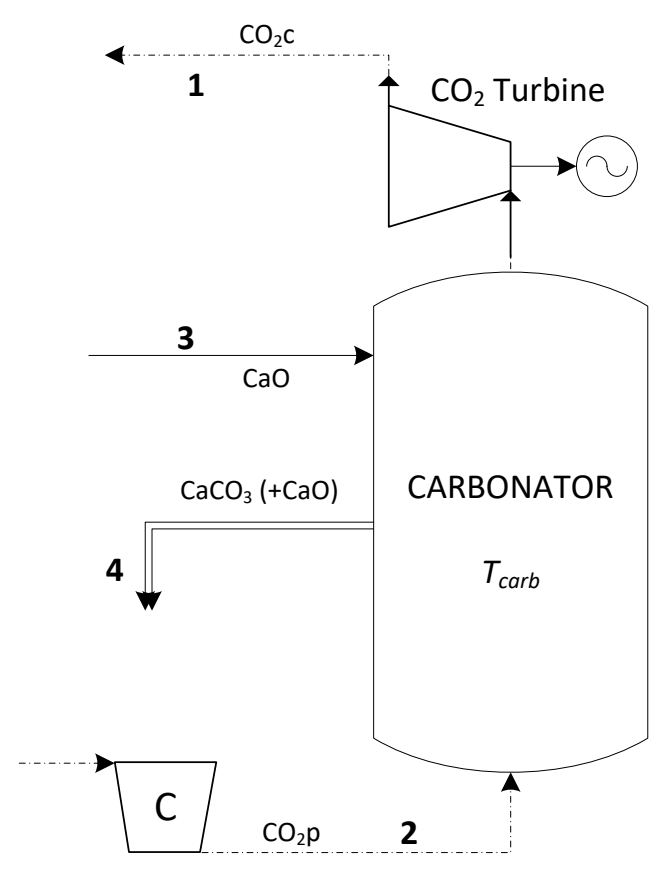

418

Figure 11: Identification of the streams in the carbonator side used for the pinch-analysis.

The average thermal capacity $F C_{p}$ of the streams is plotted in Figure 12 as a function of the value of the $\mathrm{CaO}$ conversion $X$ (referring to layout 1 ). The values are averaged between the heat exchanger input and output temperature. Exchanger HXF couples the $\mathrm{CaO}$ cold stream with the $\mathrm{CO}_{2, c}$ stream at the turbine output, while a stream of solids is used to preheat the $\mathrm{CO}_{2}, \mathrm{p}$ stream. In a countercurrent heat exchange process, the best exergy performances are obtained when thermal capacities of the two streams are identical. As can be seen in Figure 12, the exchange of heat is rather optimized for low values of $X$ while for high values of $X$ there is still room for further improvement. 


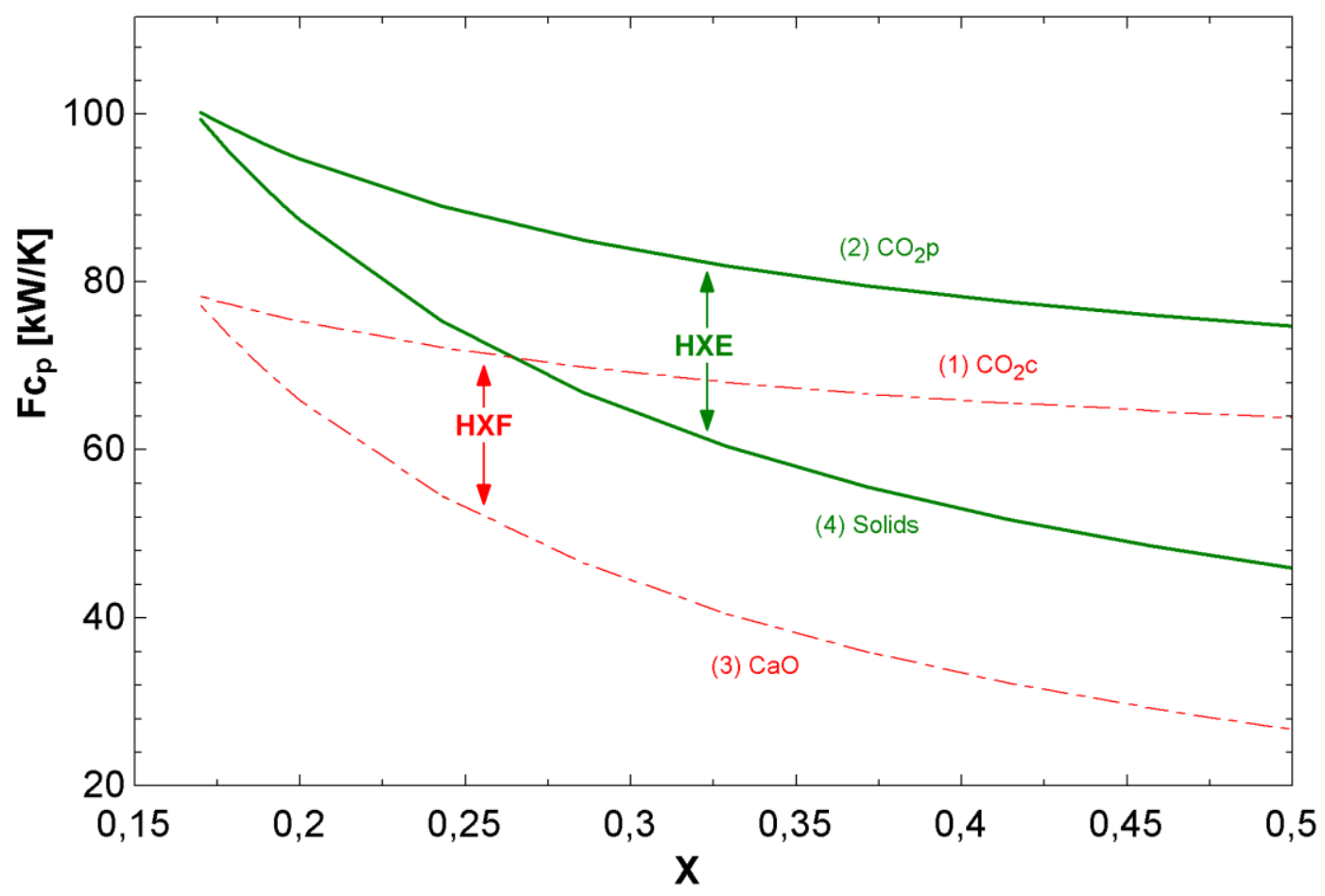

430

Figure 12: Average thermal capacity $\left(F C_{p}\right)$ of the streams in the carbonator side as indicated vs $\mathrm{CaO}$ conversion $(X)$ for HXE and HXF heat exchangers cases.

433 The targets are set in view of some considerations:

434 - The cold streams should be preheated at a temperature as high as possible before flowing 435 into the carbonator.

436 - The heat available from the carbonator effluent streams needs to be recovered. After heat recovery, such streams should be at the lowest temperature achievable.

- The lowest temperature achievable for the hot streams is ambient temperature while the target high temperature for the cold streams is the carbonator temperature. In addition, the $\mathrm{CO}_{2}$ temperature must be as low as possible at the compressor inlet in order to reduce the compression work.

The analysis based on the above considerations has been done using an ambient temperature of $20^{\circ} \mathrm{C}$, a carbonator temperature of $875^{\circ} \mathrm{C}$ and a turbine outlet temperature of $426^{\circ} \mathrm{C}$ which is the expected outlet temperature for a 7 to 0.2 bar expansion. The compressor output temperature has been set equal to ambient temperature in order to simplify calculations. This choice is justified by the fact that $\mathrm{CO}_{2}$ compression is performed with intercooling and temperature is brought down by the low-T heat available from the $\mathrm{CO}_{2}$ expansion. Table 3 shows the values of the stream parameters used in the calculations. A fixed value of $\mathrm{CaO}$ conversion $(X=0.2)$ has been employed. 
Table 3: Streams characterization for $\mathrm{X}=0.2$

456

\begin{tabular}{llllll}
\hline Stream & Type & $F c_{p}(\mathrm{~kW} / \mathrm{K})$ & $T_{\text {in }}\left({ }^{\circ} \mathrm{C}\right)$ & $T_{\text {out }}\left({ }^{\circ} \mathrm{C}\right)$ & $\Phi(\mathrm{MW})$ \\
\hline 1 & Hot & 75.3 & 426 & 30 & -29.82 \\
2 & Cold & 94.65 & 20 & 865 & 79.98 \\
3 & Cold & 65.92 & 20 & 865 & 55.7 \\
4 & Hot & 87.35 & 875 & 30 & -73.81 \\
\hline
\end{tabular}

\subsubsection{Composite curves}

458 Streams data are combined in the so-called 'composite curves', one for hot streams (defined as 459 the streams releasing heat), one for cold streams (streams requiring heat). From the composite 460 curves, it is possible to get information on the minimum heating and cooling requirements of 461 the system considered. Once the minimum heating and cooling requirements are calculated, the 462 energy targets are achieved through heat exchangers. The composite curves obtained from the 463 pinch analysis and for fixed values of $\mathrm{CaO}$ conversion in the carbonator $X=0.17, X=0.2$ and $464 X=0.5$ are shown in Figure 13. As can be seen, an additional external heat is needed to bring 465 the reactants at the carbonator temperature. On the other side, the minimum cooling 466 requirement can be interpreted as the external power that must be subtracted to the $\mathrm{CO}_{c}$ 467 stream in order to cool it down to ambient temperature before the compression stage. Both 468 469

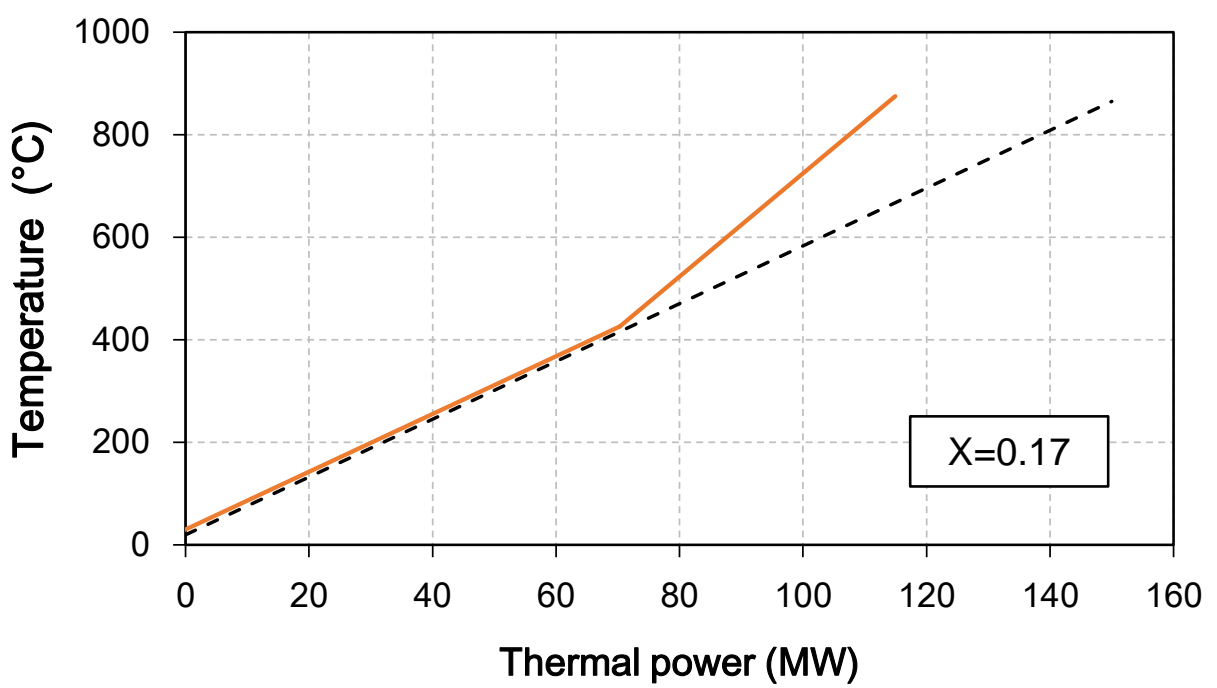



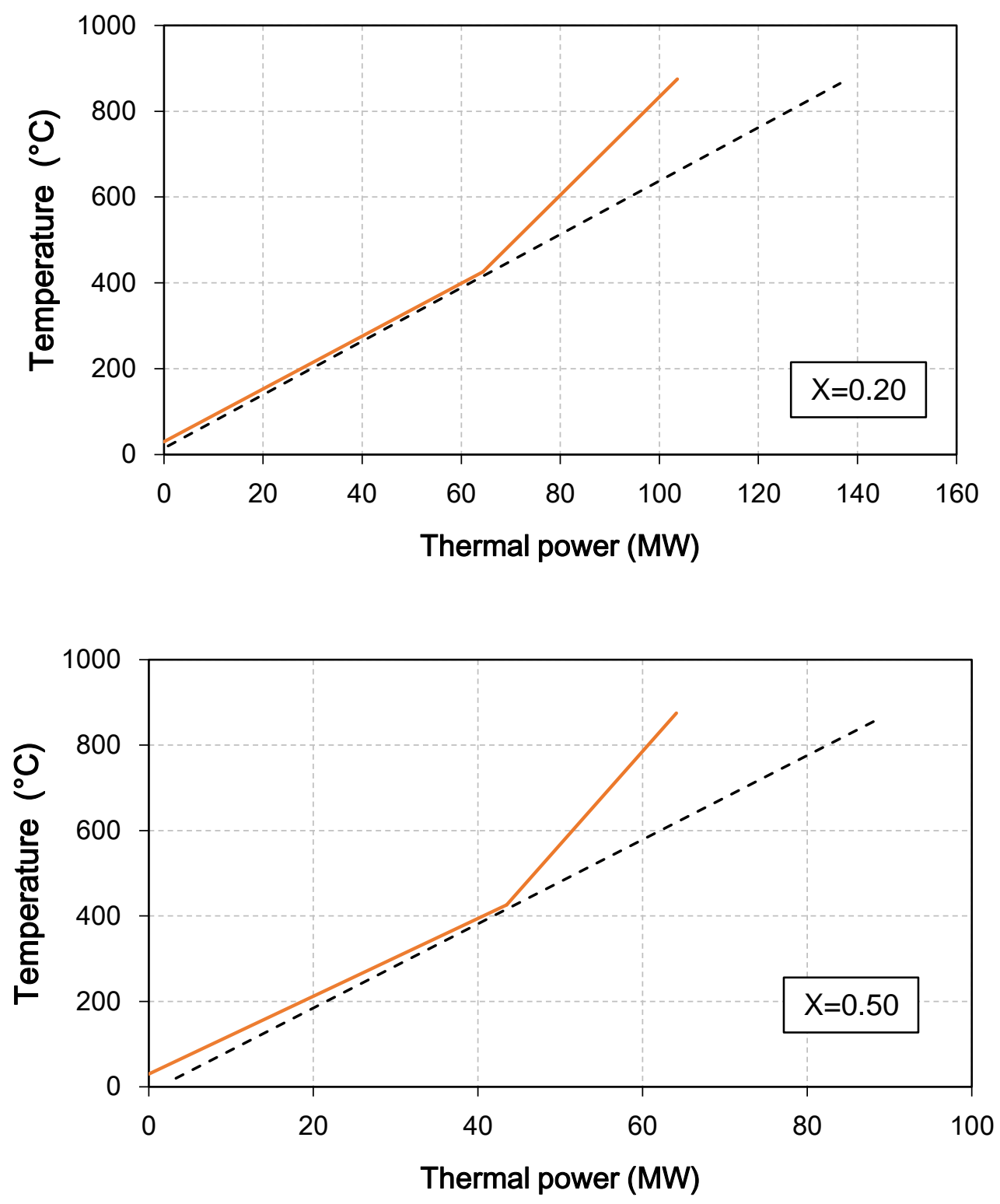

472

Figure 13: Composite curve of carbonator-side streams derived from the pinch analysis for hot streams (solid line) and cold streams (dotted line) for different values of a fixed $\mathrm{CaO}$ conversion $\mathrm{X}$.

\subsubsection{Heat exchangers network. Resulting plant}

477 The heat exchangers' network has been designed following the basic rules of pinch-analysis and 478 including some additional technical constraints:

- Coupling between the two solid streams ( $\mathrm{CaO}$ and $\left.\mathrm{CaCO}_{3}\right)$ are avoided since gas-solid and gasgas exchangers show better performance and rely on more mature technologies.

- Splitting of the solid streams is technologically much more difficult (although possible by means of pneumatic conveying) than splitting the gas streams. Thus, any splitting involves $\mathrm{CO}_{2}$ when possible.

The final goal of the analysis is to infer a network configuration that remains valid for a wide range of operating conditions. In particular, the configuration should be able to exchange the 
entire exchangeable heat (according to the minimum external heat requirement calculation) for any value of $\mathrm{CaO}$ conversion $X$ and for any pressure ratio imposed at the turbine (which

the above pinch

(H) External heater

(C) External cooler
489 490

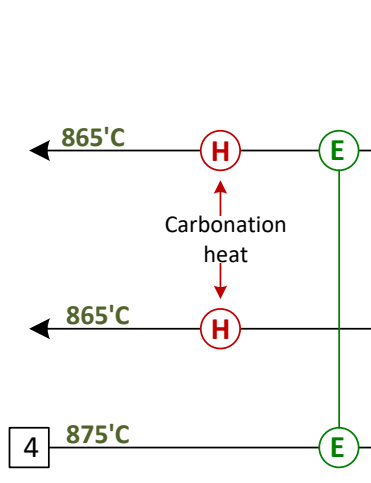

\section{4}

Figure pinch-point

temperature).

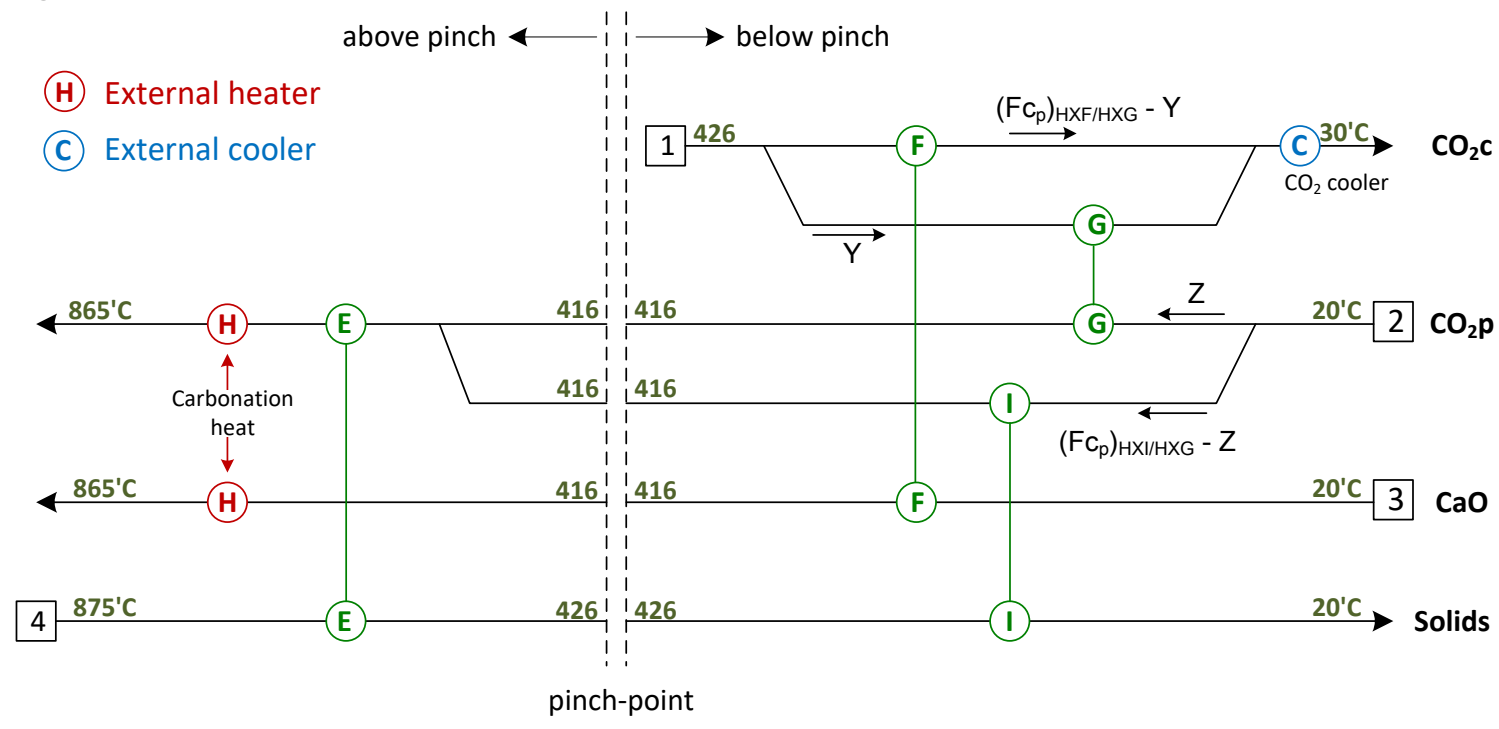

491

492

493

494

495

496

497

498

499
14

Figure 14 shows the network configuration inferred that fulfils these requirements. This configuration provides a good flexibility by splitting the two $\mathrm{CO}_{2}$ gas streams. In this way it is possible to regulate case-by-case the mass fraction in each branch. This configuration ensures also an optimal internal heat-recovery performance, with a relatively reduced number of heat exchangers and for a broad range of changes of any of the following parameters: carbonator temperature, turbine outlet temperature (or turbine pressure ratio), ambient temperature, $\mathrm{CO}_{2}$ compressor outlet temperature, $\mathrm{CaO}$ conversion and minimum temperature difference in the heat exchangers. The resulting plant is shown in Figure 15. 

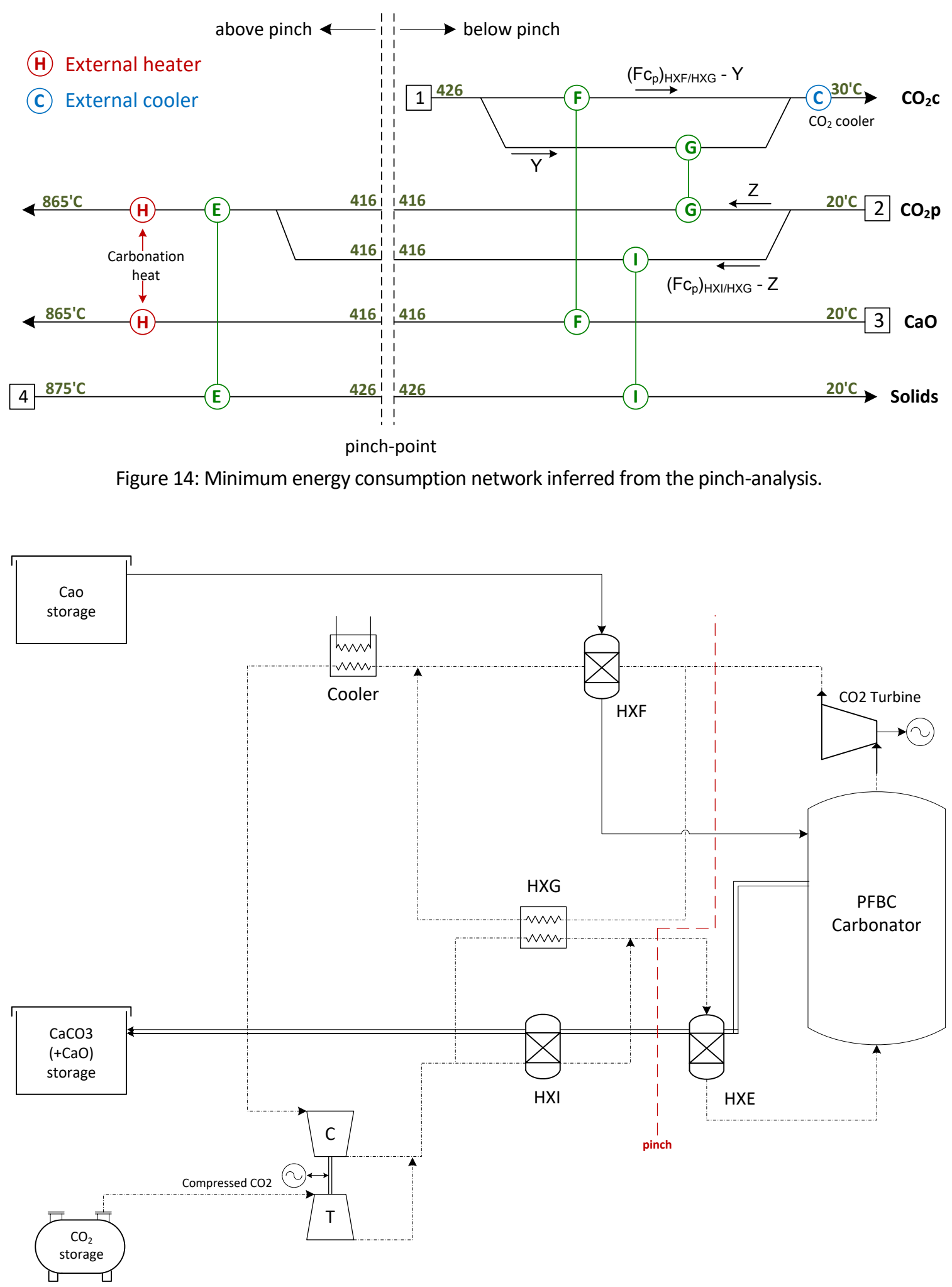

Figure 15: Plant configuration (carbonator-side) resulting from the pinch analysis

5. Optimized CaL- power cycle integration (layout 3). 
$511 \mathrm{HXF}, \mathrm{HXE}, \mathrm{HXI}$ ) and with a gas-gas regenerator (HXG). The $\mathrm{CO}_{2}$ stream from storage (produced in 512 the calciner side operation) and the $\mathrm{CO}_{2}$ stream coming from the power loop are mixed, flowing 513 through a heat exchangers train (HXG and HXI) which optimize heat recovery at low 514 temperature. On the other hand, the $\mathrm{CO}_{2}$ stream flowing out from the turbine is divided into 515 two sub-streams through HXF and $\mathrm{HXG}$ to preheat the $\mathrm{CaO}$ stream and a fraction of $\mathrm{CO}_{2}$ entering 516 into the carbonator respectively. In $\mathrm{HXE}$, the high-temperature sensible heat from the $\mathrm{CaCO}_{3}$ 517 stream is used in the final stage of $\mathrm{CO}_{2}$ stream preheating above the pinch, which serves to 518 maximize the gas temperature at the carbonator inlet and therefore the cycle performance. 519 Table 4 shows a comparison of the main data according to an energy balance for each 520 configuration. The global net efficiency increases of about $2 \%$ with respect to the base case.

Table 4: Energy balance of for the three configurations

\begin{tabular}{|c|c|c|c|c|}
\hline & Parameter & $\begin{array}{c}\text { Configuration } 1 \\
\text { (Figure 4) }\end{array}$ & $\begin{array}{c}\text { Configuration } 2 \\
\text { (Figure 9) }\end{array}$ & $\begin{array}{c}\text { Configuration } 3 \\
\text { (Figure 16) }\end{array}$ \\
\hline & Solar thermal power $\left(\mathrm{MW}_{\mathrm{th}}\right)-12 \mathrm{~h}-$ & 100 & 100 & 100 \\
\hline \multirow{7}{*}{ 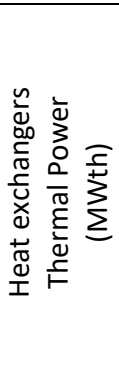 } & HXA & 120.0 & 120.0 & 120.0 \\
\hline & HXB & 23.2 & 23.2 & 23.2 \\
\hline & HXF & 26.8 & 26.8 & 46.0 \\
\hline & HXG & - & 3.4 & 78.6 \\
\hline & $\mathrm{HXI}$ & - & - & 53.7 \\
\hline & HXE & 70.4 & 67.1 & 15.5 \\
\hline & Auxiliary cooler & 3.9 & 0.6 & 6.9 \\
\hline \multirow{3}{*}{ 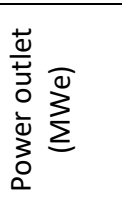 } & compressor calciner (storage) & 7.0 & 7.0 & 7.0 \\
\hline & compressor carbonator (power cycle) & 16.7 & 16.8 & 14.0 \\
\hline & Solids conveying (average) & 1.8 & 1.8 & 1.8 \\
\hline \multirow{3}{*}{ 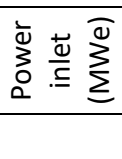 } & turbine (storage) & 1.2 & 1.2 & 2.2 \\
\hline & main turbine (power cycle) & 38.6 & 38.8 & 37.3 \\
\hline & Global net efficiency & 0.356 & 0.358 & 0.403 \\
\hline
\end{tabular}

Concerning the storage capacity, the volumetric energy density is usually expressed as the ratio between the stored thermal energy and the reactant storage volume [22]. The amount of solid stored material is highly influenced by the $\mathrm{CaO}$ conversion $(\mathrm{X})$. By considering all the tanks in the plant, for the base case of the optimized cycle (figure 16), assuming $X=0.2$, vessels volumes needed are $989.6 \mathrm{~m}^{3}, 633.7 \mathrm{~m}^{3}$ and $1227 \mathrm{~m}^{3}$ for $\mathrm{CaO}, \mathrm{CO} 2$ and solids ( $\mathrm{CaO}+\mathrm{CaCO} 3$ ) respectively. On the other hand, thermal energy production during the night from the storage reaches 2124 GJ, which implies a global energy storage density of $1.26 \mathrm{GJ} / \mathrm{m}^{3}$, still being higher than in the case of molten salts $\left(0.5 \mathrm{GJ} / \mathrm{m}^{3}\right)$ [58]. Considering power production from the storage stage, 
536 from the CaL cycle is possible to store $170.53 \mathrm{kWh} / \mathrm{m}^{3}$. In addition to the chemical storage heat, 537 the sensible heat stored in the reaction by-products is also usable. 


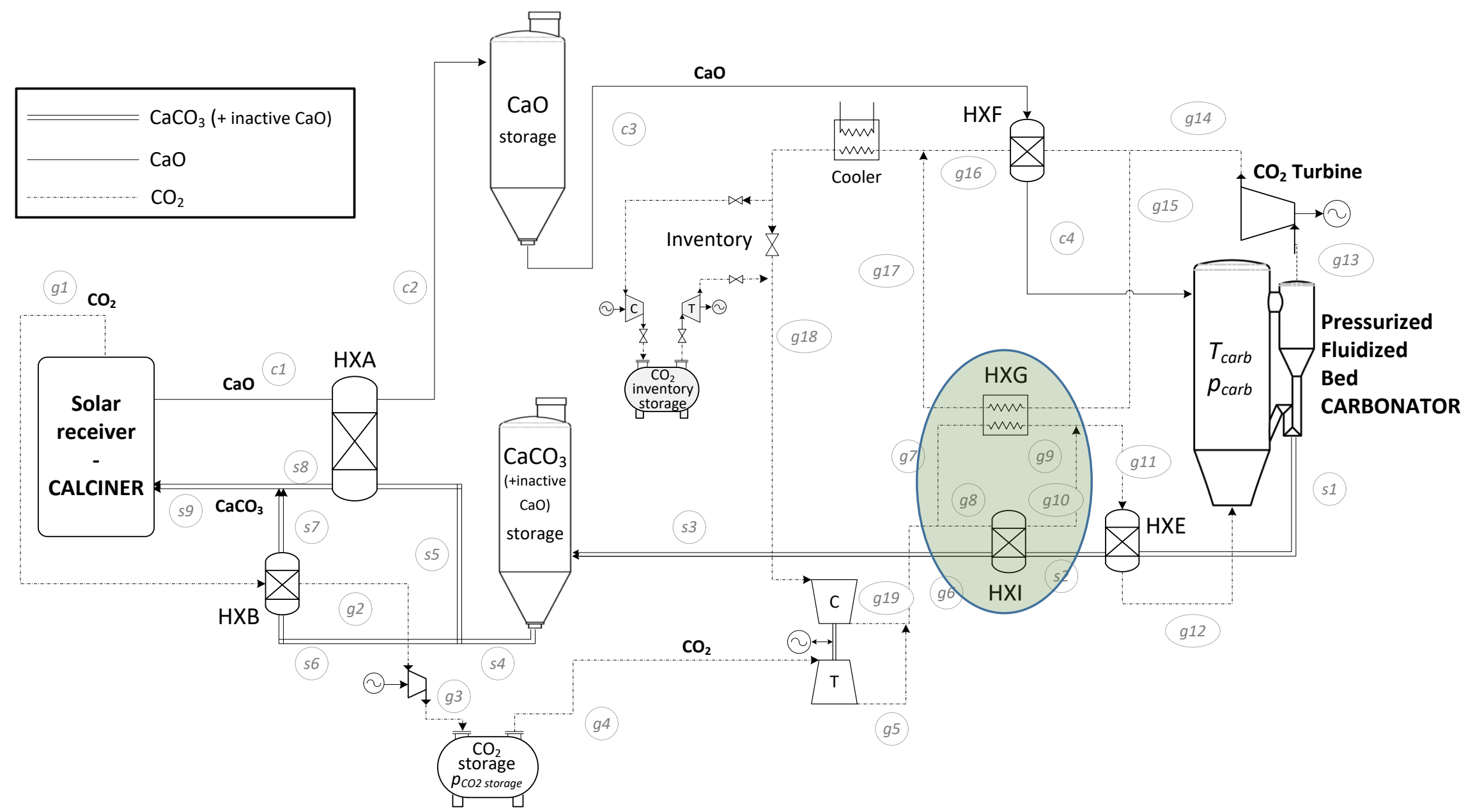


The results obtained from the model for the optimized plant configuration (Figure 16) have been analyzed as a function of $\mathrm{CaO}$ conversion $(X)$, pressure ratio $(P R)$ in the power cycle, absolute carbonator pressure $\left(P_{c a r b}\right)$ and carbonator temperature $\left(T_{c a r b}\right)$, which have been found as the critical operational parameters. Several tests have been carried out to compare the cycle efficiency with the results from the previous layouts (layout 1 in Figure 4 and layout 2 in Figure 9). For this purpose, the same model conditions (detailed in

(1)

(1)

Table 1) were used for the three layouts.

Figure 17 shows a comparison of the efficiency curves obtained for the three proposed configurations as a function of $\mathrm{CaO}$ conversion. As can be seen, the enhancement of heat recovery derived from the pinch analysis yields a relevant increase of the cycle performance (layout 3 configuration), which is improved as $\mathrm{CaO}$ conversion is increased. For layouts 1 and 2 the best performance is provided by very high values of the pressure ratio, by $\mathrm{CaO}$ conversions close to 0.2 and with overexpansion in the gas turbine. In layout 3 an optimum performance is obtained also for much smaller pressure-ratios and both atmospheric turbine outlet pressure (as may be seen in Figure 18) or atmospheric carbonator (Figure 17). Considering that rather high $\mathrm{CaO}$ conversion is foreseen to be achievable with high- $\mathrm{T}$ and high $\mathrm{CO}_{2}$ partial pressure carbonation, efficiency values close to the maximum are expected to be reached.

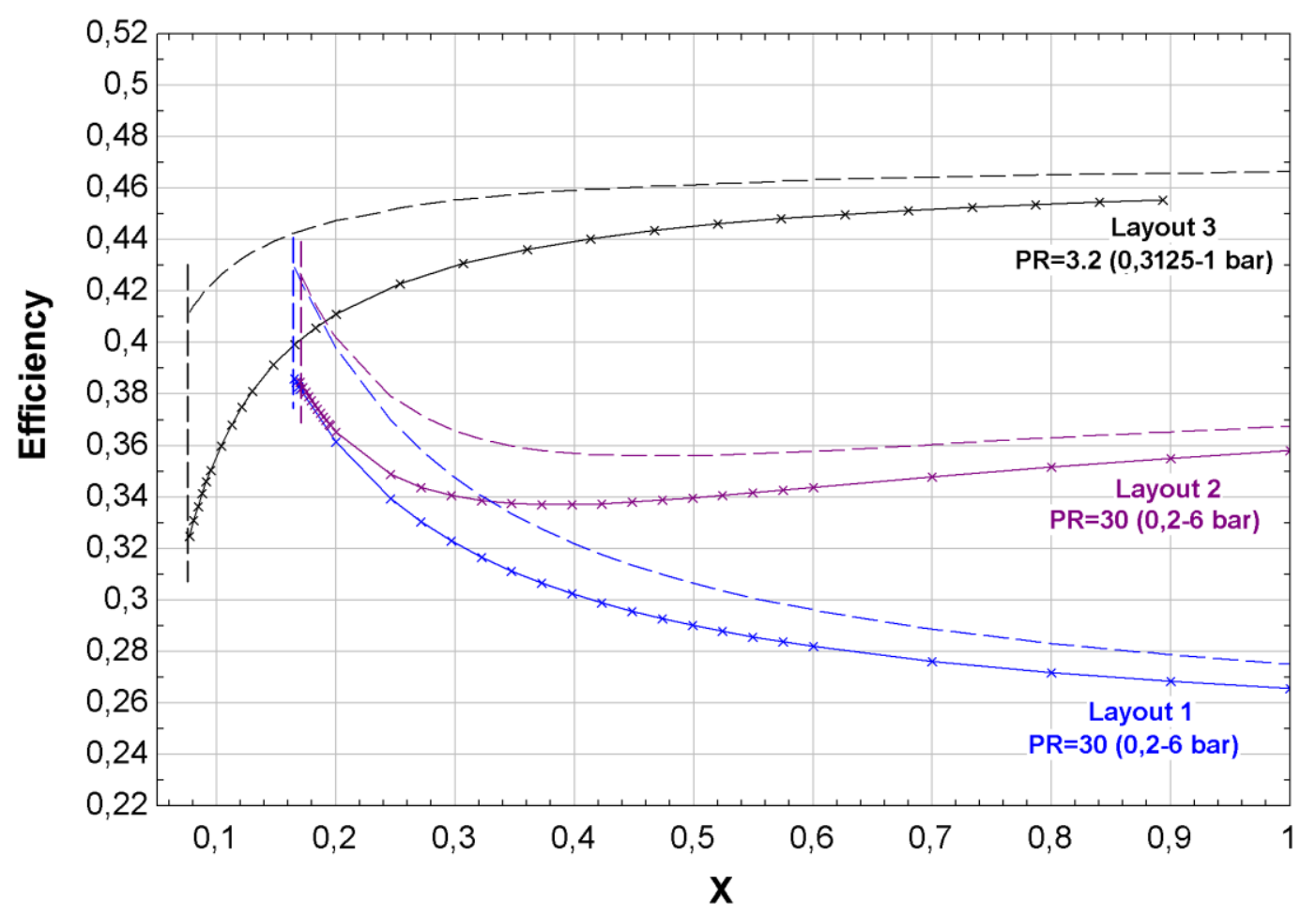




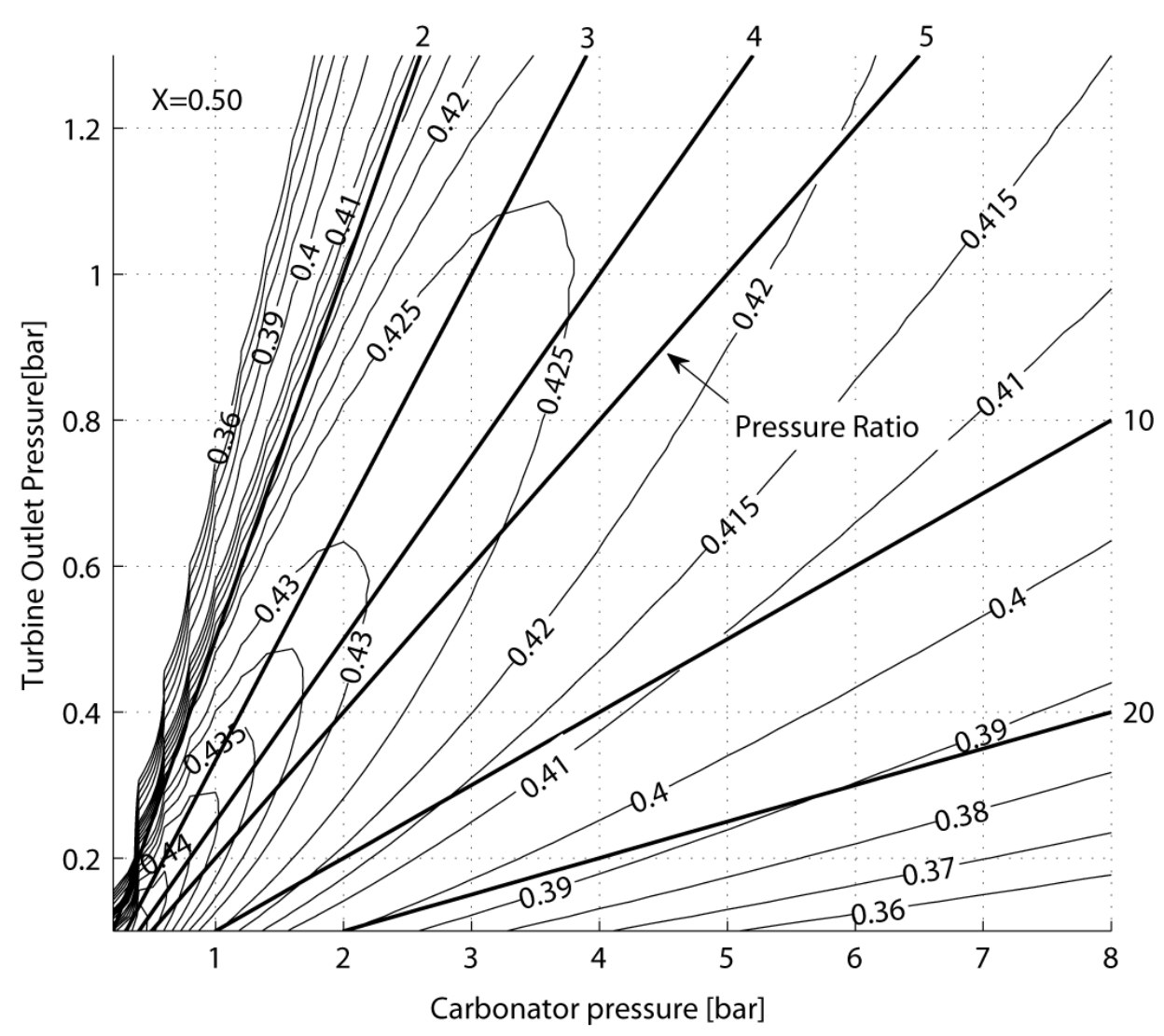

Figure 18: Contour plot of efficiency vs carbonator and turbine outlet pressure including energy consumption for solids conveying. Black lines: constant pressure ratio. Dashed white lines: iso-efficiency curves. A fixed value of $\mathrm{CaO}$ conversion $\mathrm{X}=0.50$ is used.

\section{Conclusions}

In this work, several schemes for Thermochemical Energy Storage (TCES) of Concentrated Solar Power (CSP) using the Calcium Looping (CaL) process have been analyzed. High values of global efficiency are achievable by working at high pressure ratios according to layouts 1 and 2 based on a closed $\mathrm{CO}_{2}$ Brayton cycle. High values of the carbonator to turbine outlet pressure ratio are preferably attained by over-expanding up to pressures below $1 \mathrm{~atm}$ in order to keep the carbonator absolute pressure at reasonable values (normally not exceeding 15 bar). Moreover, operation under a high carbonator pressure allows to raise the carbonation temperature (according to the reaction equilibrium), which leads consequently to higher efficiencies. In these layouts ( 1 and 2 ) higher global integration efficiencies are obtained with $\mathrm{CaO}$ conversions $(\mathrm{X})$ close to 0.2. Results from TGA experiments at realistic CSP-CaL conditions reported elsewhere show that conversion of $\mathrm{CaO}$ derived from either natural limestone or dolomite could reach residual values even higher. In layout 3, derived from a pinch-analysis thermal optimization, larger performances are predicted using much lower ratios of carbonator to turbine outlet 

increasing trend with $\mathrm{CaO}$ conversion.

\section{Acknowledgements}

592

This work was supported by the Spanish Government Agency Ministerio de Economia y

594

\section{Notation}

\begin{tabular}{|c|c|c|c|}
\hline$c_{p, i}$ & specific heat, $\mathrm{kJ} /(\mathrm{kmol} \cdot \mathrm{K})$ & HXI & gas-solid heat exchanger \\
\hline$E$ & fraction of $\mathrm{CO}_{2}$ spent in the reaction & $\dot{m}_{\mathrm{CO} 2, \mathrm{crb}}$ & $\mathrm{CO}_{2}$ mass flow rate through carbonator \\
\hline$F_{i}$ & molar flow rate of component $\mathrm{i}, \mathrm{kmol} / \mathrm{s}$ & $P_{c a r b}$ & absolute carbonator pressure, bar \\
\hline $\mathrm{F}_{\mathrm{CaCO}_{3}}$ & $\mathrm{CaCO}_{3}$ molar flow rate & $P_{e q}$ & $\mathrm{CO}_{2}$ partial pressure at equilibrium, bar \\
\hline$F_{\mathrm{CaCO}, \mathrm{carb}}$ & $\mathrm{CaCO}_{3}$ molar flow rate (calciner side) & $P R$ & pressure ratio \\
\hline$F_{\mathrm{CaCO}, \mathrm{clc}}$ & $\mathrm{CaCO}_{3}$ molar flow rate (carbonator side) & $p_{\text {drop }}$ & pressure drops of $\mathrm{CO}_{2}$, bar \\
\hline$F_{C a O, c r b}$ & molar flow rate of $\mathrm{CaO}$ & $y_{C O 2, c a r b, i n}$ & inlet molar fraction of $\mathrm{CO}_{2}$ in the carbonator \\
\hline$F_{C a O, c l c}$ & mole of regenerated sorbent & $y_{e q}$ & equilibrium fraction of $\mathrm{CO}_{2}$ in the carbonator \\
\hline$F_{C a O, n r, c a r b}$ & $\begin{array}{c}\text { molar flow rate of unreacted } \mathrm{CaO} \\
\text { (carbonator side) }\end{array}$ & $T$ & Temperature, ${ }^{\circ} \mathrm{C}$ \\
\hline$F_{C a O, n r, c l c}$ & $\begin{array}{c}\text { molar flow rate of unreacted } \mathrm{CaO} \\
\text { (calciner side) }\end{array}$ & $T_{c l c}$ & Calciner temperature, ${ }^{\circ} \mathrm{C}$ \\
\hline$F_{\mathrm{CO}_{2}, \mathrm{clc}, \mathrm{out}}$ & $\mathrm{CO}_{2}$ molar flow rate at calciner outlet & $T_{\text {carb }}$ & Carbonator temperature, ${ }^{\circ} \mathrm{C}$ \\
\hline$F_{\mathrm{CO}_{2}, n r}$ & $\begin{array}{l}\text { Non reacted } \mathrm{CO}_{2} \text { molar flow in the } \\
\text { carbonator }\end{array}$ & $v_{i}$ & Stoichiometric coefficient of compound $i$. \\
\hline$F_{R, c a r b}$ & $\begin{array}{l}\text { recirculating molar flow rate (carbonator } \\
\text { side) }\end{array}$ & $\dot{W}$ & Mechanical power, kW \\
\hline$F_{R, c l c}$ & $\begin{array}{l}\text { recirculating molar flow rate (calciner } \\
\text { side) }\end{array}$ & $X$ & average $\mathrm{CaO}$ conversion \\
\hline$F_{\mathrm{CO}_{2}, \text { stoich }}$ & Stoichiometric $\mathrm{CO}_{2}$ molar flow & $\Delta t_{\text {sun }}$ & average daytime period (h) \\
\hline$h_{i}$ & Enthalpy, kJ/kmol & $\Delta H_{R}\left(T_{\text {react }}\right)$ & $\begin{array}{l}\text { reaction enthalpy at the reactor } \\
\text { temperature, } \mathrm{kJ} / \mathrm{mol}\end{array}$ \\
\hline HXA & solid-solid heat exchanger & $\Delta H_{R}{ }^{0}$ & standard enthalpy of reaction, $\mathrm{kJ} / \mathrm{mol}$ \\
\hline HXB & gas-solid heat exchanger & $\xi$ & extent of reaction per unit time \\
\hline HXE & gas-solid heat exchanger & $\Phi$ & Thermal power, KW \\
\hline HXF & gas-solid heat exchanger & $\Phi_{\text {disp }}$ & Dissipated heat of carbonation, kW \\
\hline HXG & gas-gas heat exchanger & & \\
\hline
\end{tabular}

Appendix A. Main stream data for the base case of each CSP-CaL configuration

Table 5: Main stream data for the base case of each CSP-CaL configuration

\begin{tabular}{|c|c|c|c|c|c|c|c|c|c|}
\hline $\begin{array}{c}\text { stream } \\
\text { ID }\end{array}$ & \multicolumn{3}{|c|}{$\begin{array}{c}\text { Configuration 1 } \\
\text { (Figure 4) - PR=30, X=0.2 }\end{array}$} & \multicolumn{3}{c|}{$\begin{array}{c}\text { Configuration 2 } \\
\text { (Figure 9) - PR=30, X=0.2 }\end{array}$} & \multicolumn{3}{c|}{$\begin{array}{c}\text { Configuration 3 } \\
\text { (Figure 16) }-\mathrm{PR}=3.2, \mathrm{X}=0.2\end{array}$} \\
\hline & $P($ bar $)$ & $T\left({ }^{\circ} \mathrm{C}\right)$ & $\dot{m}(\mathrm{~kg} / \mathrm{s})$ & $P($ bar $)$ & $T\left({ }^{\circ} \mathrm{C}\right)$ & $\dot{m}(\mathrm{~kg} / \mathrm{s})$ & $P($ bar $)$ & $T\left({ }^{\circ} \mathrm{C}\right)$ & $\dot{m}(\mathrm{~kg} / \mathrm{s})$ \\
\hline $\mathrm{s} 1$ & 1.01 & 875 & 88.5 & 1.01 & 875 & 88.5 & 1.01 & 875 & 88.5 \\
\hline $\mathrm{s} 2$ & 1.01 & 68 & 88.5 & 1.01 & 110 & 88.5 & 1.01 & 708.8 & 88.5 \\
\hline $\mathrm{s} 3$ & 1.01 & 20 & 177.0 & 1.01 & 20 & 177.0 & 1.01 & 83.0 & 88.5 \\
\hline s4 & 1.01 & 20 & 146.3 & 1.01 & 20 & 146.3 & 1.01 & 20 & 177.1 \\
\hline s5 & 1.01 & 20 & 30.7 & 1.01 & 20 & 30.7 & 1.01 & 20 & 146.3 \\
\hline s6 & 1.01 & 802.9 & 30.7 & 1.01 & 802.9 & 30.7 & 1.01 & 20 & 30.7 \\
\hline s7 & 1.01 & 863 & 146.3 & 1.01 & 863 & 146.3 & 1.01 & 802.9 & 30.7 \\
\hline
\end{tabular}




\begin{tabular}{|c|c|c|c|c|c|c|c|c|c|}
\hline s8 & 1.01 & 852.6 & 177.0 & 1.01 & 852.6 & 177.0 & 1.01 & 863 & 146.3 \\
\hline s9 & - & - & - & - & - & - & 1.01 & 852.6 & 177.1 \\
\hline c1 & 1.01 & 900 & 153.0 & 1.01 & 900 & 153.0 & 1.01 & 900 & 153.0 \\
\hline c2 & 1.01 & 40 & 153.0 & 1.01 & 40 & 153.0 & 1.01 & 40 & 153.0 \\
\hline c3 & 1.01 & 20 & 76.5 & 1.01 & 20 & 76.6 & 1.01 & 20 & 76.5 \\
\hline c4 & 1.01 & 427.2 & 76.5 & 1.01 & 427.2 & 76.6 & 1.01 & 693.9 & 76.5 \\
\hline g1 & 1.01 & 900 & 24.0 & 1.01 & 900 & 24.0 & 1.01 & 900 & 24.0 \\
\hline g2 & 1.01 & 35 & 24.0 & 1.01 & 35 & 24.0 & 1.01 & 35 & 24.0 \\
\hline g3 & 75 & 40 & 24.0 & 75 & 40 & 24.0 & 75 & 40 & 24.0 \\
\hline g4 & 75 & 20 & 12.0 & 75 & 20 & 12.0 & 75 & 20 & 12.0 \\
\hline g5 & 6 & 10.8 & 12.0 & 6 & 10.8 & 12.0 & 1 & -1.3 & 12.0 \\
\hline g6 & 6 & 53 & 85.8 & 6 & 53 & 85.8 & 1 & 56.5 & 191.3 \\
\hline g7 & 6 & 795.6 & 85.8 & 6 & 53 & 9.0 & 1 & 56.5 & 113.6 \\
\hline g8 & 6 & 875 & 73.8 & 6 & 53 & 76.7 & 1 & 56.5 & 77.7 \\
\hline g9 & 0.2 & 442.2 & 73.8 & 6 & 427.2 & 9.0 & 1 & 693.8 & 113.6 \\
\hline g10 & 0.2 & 90.1 & 73.8 & 6 & 796 & 85.8 & 1 & 693.8 & 77.7 \\
\hline g11 & 0.2 & 30 & 73.8 & 6 & 875 & 73.8 & 1 & 693.8 & 191.3 \\
\hline g12 & 6 & 59.6 & 73.8 & 0.2 & 442.2 & 73.8 & 1 & 759.7 & 191.3 \\
\hline g13 & - & - & - & 0.2 & 442.2 & 8.9 & 1 & 875 & 179.3 \\
\hline g14 & - & - & - & 0.2 & 442.2 & 64.9 & 0.313 & 708.9 & 179.3 \\
\hline g15 & - & - & - & 0.2 & 35 & 64.9 & 0.313 & 708.9 & 115.1 \\
\hline g16 & - & - & - & 0.2 & 68 & 8.9 & 0.313 & 49.9 & 64.2 \\
\hline g17 & - & - & - & 0.2 & 30 & 73.8 & 0.313 & 87.1 & 115.1 \\
\hline g18 & - & - & - & 6 & 59.61 & 73.8 & 0.313 & 30 & 179.3 \\
\hline g19 & - & - & - & - & - & - & 1 & 60.2 & 179.3 \\
\hline & & & & & & & & & \\
\hline
\end{tabular}

\section{References}

601 [1] United Nations. Framework Convention on Climate Change. Adoption of the Paris Agreement. vol. 21932. 2015.

[2] International Energy Agency. Technology Roadmap Solar Thermal Electricity 2014:52.

[3] Panwar NL, Kaushik SC, Kothari S. Role of renewable energy sources in environmental doi:10.1007/SpringerReference_7300. protection: A review. Renew Sustain Energy Rev 2011;15:1513-24.

[4] Arce P, Medrano M, Gil A, Oró E, Cabeza LF. Overview of thermal energy storage (TES) potential energy savings and climate change mitigation in Spain and Europe. Appl Energy 2011;88:2764-74. doi:10.1016/j.apenergy.2011.01.067.

[5] Kuravi S, Trahan J, Goswami DY, Rahman MM, Stefanakos EK. Thermal energy storage technologies and systems for concentrating solar power plants. Prog Energy Combust Sci 2013;39:285-319. doi:10.1016/j.pecs.2013.02.001.

Denholm P, O'Connell M, Brinkman G, Jorgenson J. Overgeneration from Solar Energy in California: A Field Guide to the Duck Chart (NREL/TP-6A20-65023) 2015:46.

Paksoy HÖ. Thermal Energy Storage for Sustainable Energy Consumption. 2007.

Mahlia TMI, Saktisahdan TJ, Jannifar a., Hasan MH, Matseelar HSC. A review of available methods and development on energy storage; Technology update. Renew Sustain Energy Rev 2014;33:532-45. doi:10.1016/j.rser.2014.01.068. 2014;32:591-610. doi:10.1016/j.rser.2013.12.014. 
[10] Kearney D, Kelly B, Herrmann U, Cable R, Pacheco J, Mahoney R, et al. Engineering aspects of a molten salt heat transfer fluid in a trough solar field. Energy 2004;29:86170. doi:10.1016/S0360-5442(03)00191-9.

[11] Fernández AG, Ushak S, Galleguillos H, Pérez FJ. Development of new molten salts with LiNO3 and $\mathrm{Ca}(\mathrm{NO} 3) 2$ for energy storage in CSP plants. Appl Energy 2014;119:131-40. doi:10.1016/j.apenergy.2013.12.061.

[12] Rodríguez I, Pérez-Segarra CD, Lehmkuhl O, Oliva A. Modular object-oriented methodology for the resolution of molten salt storage tanks for CSP plants. Appl Energy 2013;109:402-14. doi:10.1016/j.apenergy.2012.11.008.

[13] Chacartegui R, Vigna L, Becerra JA, Verda V. Analysis of two heat storage integrations for an Organic Rankine Cycle Parabolic trough solar power plant. Energy Convers Manag 2016. doi:10.1016/j.enconman.2016.03.067.

[14] Kuravi S, Goswami DY, Stefanakos EK, Ram M, Jotshi C, Trahan J, et al. THERMAL ENERGY STORAGE FOR CONCENTRATING SOLAR POWER PLANTS Sarada Kuravi, D. Yogi Goswami, Elias K. Stefanakos, Manoj Ram, Chand Jotshi, Swetha Pendyala, Jamie Trahan, Prashanth Sridharan, Muhammad Rahman and Burton Krakow Clean Energy Research Center, U n.d.

[15] Karagiannakis G, Pagkoura C, Zygogianni A, Lorentzou S, Konstandopoulos AG. Monolithic Ceramic Redox Materials for Thermochemical Heat Storage Applications in CSP Plants. Energy Procedia 2014;49:820-9. doi:10.1016/j.egypro.2014.03.089.

[16] Medrano M, Gil A, Martorell I, Potau X, Cabeza LF. State of the art on high-temperature thermal energy storage for power generation. Part 2-Case studies. Renew Sustain Energy Rev 2010;14:56-72. doi:10.1016/j.rser.2009.07.036.

[17] Zalba B, Marín JM, Cabeza LF, Mehling H. Review on thermal energy storage with phase change: materials, heat transfer analysis and applications. vol. 23. 2003. doi:10.1016/S1359-4311(02)00192-8.

[18] Tian Y, Zhao CY. A review of solar collectors and thermal energy storage in solar thermal applications. Appl Energy 2013;104:538-53. doi:10.1016/j.apenergy.2012.11.051.

[19] Nithyanandam K, Pitchumani R. Design of a latent thermal energy storage system with embedded heat pipes. Appl Energy 2014;126:266-80. doi:10.1016/j.apenergy.2014.03.025.

[20] Nithyanandam K, Pitchumani R. Cost and performance analysis of concentrating solar power systems with integrated latent thermal energy storage. Energy 2014;64:793810. doi:10.1016/j.energy.2013.10.095.

[21] Sharma A, Tyagi VV, Chen CR, Buddhi D. Review on thermal energy storage with phase change materials and applications. Renew Sustain Energy Rev 2009;13:318-45. doi:10.1016/j.rser.2007.10.005.

[22] Pardo P, Deydier a., Anxionnaz-Minvielle Z, Rougé S, Cabassud M, Cognet P. A review on high temperature thermochemical heat energy storage. Renew Sustain Energy Rev 2014;32:591-610. doi:10.1016/j.rser.2013.12.014.

[23] Li TX, Wu S, Yan T, Xu JX, Wang RZ. A novel solid-gas thermochemical multilevel sorption thermal battery for cascaded solar thermal energy storage. Appl Energy 2016;161:1-10. doi:10.1016/j.apenergy.2015.09.084. 
[24] Chacartegui R, Alovisio A, Ortiz C, Valverde JM, Verda V, Becerra JA. Thermochemical energy storage of concentrated solar power by integration of the calcium looping process and a CO2 power cycle. Appl Energy 2016;173:589-605. doi:10.1016/j.apenergy.2016.04.053.

[25] Neveu P, Tescari S, Aussel D, Mazet N. Combined constructal and exergy optimization of thermochemical reactors for high temperature heat storage. Energy Convers Manag 2013;71:186-98. doi:10.1016/j.enconman.2013.03.035.

[26] N'Tsoukpoe KE, Liu H, Le Pierrès N, Luo L. A review on long-term sorption solar energy storage. Renew Sustain Energy Rev 2009;13:2385-96. doi:10.1016/j.rser.2009.05.008.

[27] Wentworth WE, Chen E. Simple Thermal Decomposition Reactions for Storage of Solar Thermal Energy. Sol Energy 1976;18:205-14. doi:10.1016/0038-092X(76)90019-0.

[28] Barker R. The reactivity of calcium oxide towards carbon dioxide and its use for energy storage. J Appl Chem Biotechnol 1974;24:221-7. doi:10.1002/jctb.2720240405.

[29] Abedin A, Rosen M. A Critical Review of Thermochemical Energy Storage Systems. Open Renew Energy J n.d.:42-6. doi:10.2174/1876387101004010042.

[30] Edwards SEB, Materić V. Calcium looping in solar power generation plants. Sol Energy 2012;86:2494-503. doi:10.1016/j.solener.2012.05.019.

[31] Sakellariou KG, Karagiannakis G, Criado YA, Konstandopoulos AG. Calcium oxide based materials for thermochemical heat storage in concentrated solar power plants. Sol Energy 2015;122:215-30. doi:10.1016/j.solener.2015.08.011.

[32] Dunsmore HE. A geological perspective on global warming and the possibility of carbon dioxide removal as calcium carbonate mineral. Energy Convers Manag 1992;33:565-72. doi:10.1016/0196-8904(92)90057-4.

[33] Ortiz C, Chacartegui R, Valverde J, Becerra J, Perez-Maqueda L. A new model of the carbonator reactor in the calcium looping technology for post-combustion $\mathrm{CO} 2$ capture. FUEL 2015;160:328-38. doi:10.1016/j.fuel.2015.07.095.

[34] Ylätalo J, Parkkinen J, Ritvanen J, Tynjälä T, Hyppänen T. Modeling of the oxycombustion calciner in the post-combustion calcium looping process. Fuel 2013;113:770-9. doi:10.1016/j.fuel.2012.11.041.

[35] Sanchez-Jimenez PE, Valverde JM, Perez-Maqueda L. Multicyclic conversion of limestone at Ca-looping conditions: The role of solid-sate diffusion controlled carbonation. Fuel 2014;127:131-40. doi:10.1016/j.fuel.2013.09.064.

[36] Valverde JM. Relevant Influence of Limestone Crystallinity on CO2 Capture in The CaLooping Technology at Realistic Calcination Conditions 2014.

[37] Valverde JM, Sanchez-Jimenez PE, Perez-Maqueda L. Calcium-looping for postcombustion $\mathrm{CO} 2$ capture. On the adverse effect of sorbent regeneration under $\mathrm{CO} 2$. Appl Energy 2014;126:161-71. doi:10.1016/j.apenergy.2014.03.081.

[38] Sarrion B, Valverde JM, Perejon A, Perez-maqueda LA, Sanchez-jimenez PE. On the multicycle activity of natural limestone/dolomite for cheap, efficient and non-toxic Thermochemical Energy Storage of Concentrated Solar Power. Energy Technol 2016. doi:10.1002/ente.201600068.

[39] Tregambi C, Montagnaro F, Salatino P, Solimene R. A model of integrated calcium looping for CO2 capture and concentrated solar power. Sol Energy 2015;120:208-20. 
[40] Zhai R, Li C, Qi J, Yang Y. Thermodynamic analysis of CO2 capture by calcium looping process driven by coal and concentrated solar power. Energy Convers Manag 2016;117:251-63. doi:10.1016/j.enconman.2016.03.022.

[41] Muñoz-Antón J, Rubbia C, Rovira A, Martínez-Val JM. Performance study of solar power plants with $\mathrm{CO} 2$ as working fluid. A promising design window. Energy Convers Manag 2015;92:36-46. doi:10.1016/j.enconman.2014.12.030.

[42] Barin I. Thermochemical data of pure substances VCH, Weinheim (1989) 1989.

[43] Charitos A, Rodríguez N, Hawthorne C, Alonso M, Zieba M, Arias B, et al. Experimental Validation of the Calcium Looping CO2 Capture Process with Two Circulating Fluidized

[44] Arias B, Diego ME, Abanades JC, Lorenzo M, Diaz L, Martínez D, et al. Demonstration of steady state $\mathrm{CO} 2$ capture in a 1.7MWth calcium looping pilot. Int J Greenh Gas Control 2013;18:237-45. doi:10.1016/j.ijggc.2013.07.014.

[45] Ströhle J, Junk M, Kremer J, Galloy A, Epple B. Carbonate looping experiments in a 1 MWth pilot plant and model validation. Fuel 2014;127:13-22. doi:10.1016/j.fuel.2013.12.043.

[46] Meier A, Bonaldi E, Cella GM, Lipinski W, Wuillemin D. Solar chemical reactor technology for industrial production of lime. Sol Energy 2006;80:1355-62. doi:10.1016/j.solener.2005.05.017.

[47] Badie JM, Bonet C, Faure M, Flamant G, Foro R, Hernandez D. 52 Decarbonation of calcite and phosphate rock in solar chemical reactors. Chem Eng Sci 1980;35:413-20. doi:10.1016/0009-2509(80)80114-X.

[48] Meier A, Bonaldi E, Cella GM, Lipinski W, Wuillemin D, Palumbo R. Design and experimental investigation of a horizontal rotary reactor for the solar thermal production of lime. Energy 2004;29:811-21. doi:10.1016/S0360-5442(03)00187-7.

[49] Meier A, Bonaldi E, Cella GM, Lipinski W. Multitube Rotary Kiln for the Industrial Solar Production of Lime. J Sol Energy Eng 2005;127:386. doi:10.1115/1.1979517.

[50] Imhof a. Decomposition of limestone in a solar reactor. Renew Energy 1996;9:661-3. doi:10.1016/0960-1481(96)88373-X.

[51] de Bosio F, Verda V. Thermoeconomic analysis of a Compressed Air Energy Storage (CAES) system integrated with a wind power plant in the framework of the IPEX Market. Appl Energy 2015;152:173-82. doi:10.1016/j.apenergy.2015.01.052.

[52] Mills D. Pneumatic conveying design guide 2004:80.

[53] Yu FC, Fan LS. Kinetic Study of High-Pressure Carbonation Reaction of Calcium-Based Sorbents in the Calcium Looping Process (CLP). Ind Eng Chem Res 2011;50:11528-36. doi:Doi 10.1021/le200914e.

[54] Yan X. Dynamic Analysis and Control System Design for an Advanced Nuclear Gas Turbine Power Plant. Massachusetts Institute of Technology, 1990.

[55] Sánchez D, Chacartegui R, Muñoz De Escalona JM, Muñoz A, Sánchez T. Performance analysis of a MCFC \& supercritical carbon dioxide hybrid cycle under part load operation. Int J Hydrogen Energy 2011;36:10327-36. 
doi:10.1016/j.ijhydene.2010.09.072.

[56] Olumayegun O, Wang M, Kelsall G. Closed-cycle gas turbine for power generation: A state-of-the-art review. Fuel 2016;180:694-717. doi:10.1016/j.fuel.2016.04.074.

754

755

[57] Linnhoff $B$, Hindmarsh E. The pinch design method for heat exchanger networks. Chem Eng Sci 1983;38:745-63. doi:10.1016/0009-2509(83)80185-7.

[58] Janz GJ, Allen, Carolyn B, Bansal NP, Murphy RM, Tomkins RP. Physical Properties Data Compilations Relevant to Energy Storage. II. Molten Salts: Data on Single and MultiComponents Salt Systems. Natl Bur Stand 1979. 